DIW BERLIN

Discussion

Papers

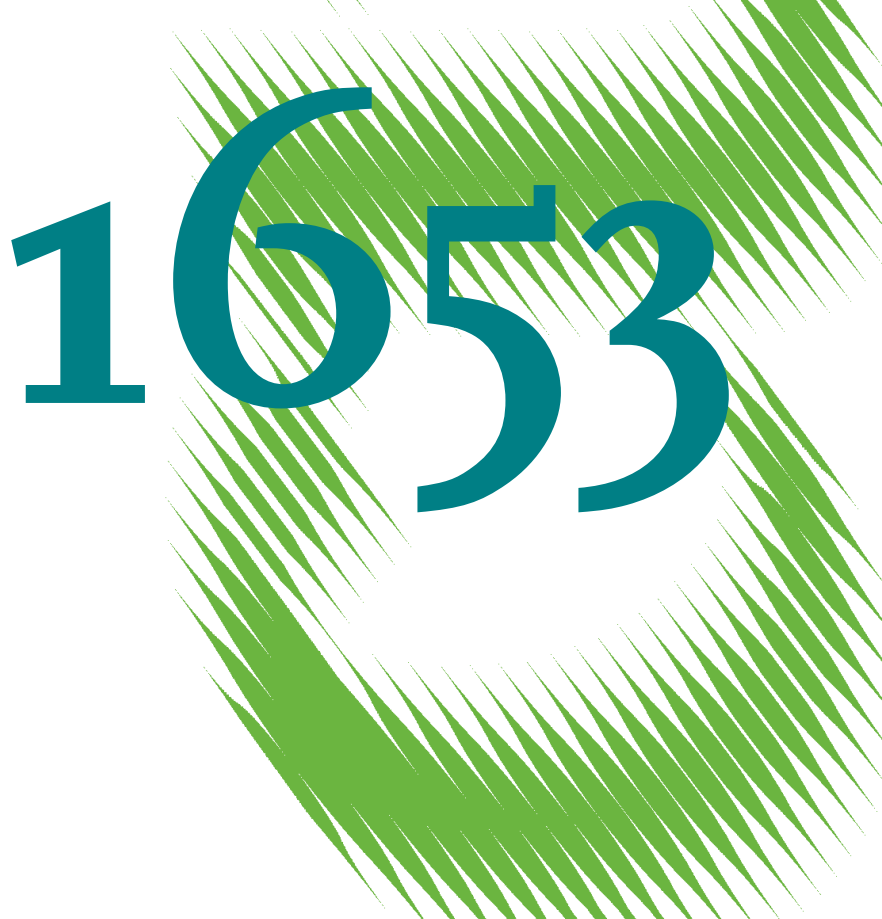

Closing Routes to Retirement:

How Do People Respond? 
Opinions expressed in this paper are those of the author(s) and do not necessarily reflect views of the institute.

IMPRESSUM

(C) DIW Berlin, 2017

DIW Berlin

German Institute for Economic Research

Mohrenstr. 58

10117 Berlin

Tel. +49 (30) $89789-0$

Fax +49 (30) $89789-200$

http://www.diw.de

ISSN electronic edition 1619-4535

Papers can be downloaded free of charge from the DIW Berlin website:

http://www.diw.de/discussionpapers

Discussion Papers of DIW Berlin are indexed in RePEc and SSRN:

http://ideas.repec.org/s/diw/diwwpp.html

http://www.ssrn.com/link/DIW-Berlin-German-Inst-Econ-Res.html 


\title{
Closing routes to retirement: how do people respond?*
}

\author{
Johannes Geyer’ Clara Welteke
}

March 19, 2017

\begin{abstract}
We present quasi-experimental evidence on the employment effects of an unprecedented large increase in the early retirement age (ERA). Raising the ERA has the potential to extend contribution periods and to reduce the number of pension beneficiaries at the same time, if employment exits are successfully delayed. However, workers may not be able to work longer or may choose other social support programs as exit routes from employment. We study the effects of the ERA increase on employment and potential program substitution in a regression-discontinuity framework. Germany abolished an important early retirement program for women born after 1951, effectively raising the ERA for women by three years. We analyze the effects of this huge increase on employment, unemployment, disability pensions, and inactivity rates. Our results suggest that the reform increased both employment and unemployment rates of women age 60 and over. However, we do not find evidence for active program substitution from employment into alternative social support programs. Instead employed women remained employed and unemployed women remained unemployed. The results suggest an increase in inequality within the affected cohorts.
\end{abstract}

Keywords: Retirement age, Early retirement, Regression discontinuity, Pension reform, Unemployment, Labor supply, Disability pension

JEL Classification: J14, J18, J22, J26

\footnotetext{
${ }^{*}$ We thank David Blau, Flavia Coda-Moscarola, Gordon Dahl, Peter Haan, Markus Knell, Rafael Lalive, Adam Lederer, Maarten Lindeboom, and Arthur Seibold, and numerous seminar and conference participants for insightful comments and suggestions. We are grateful for the support of Tatjana Mika, Wolfgang Keck, and their colleagues at the Research Data Centre of the German Pension Insurance. Clara Welteke acknowledges funding from the Research Network of the German Pension Insurance Fund through a doctoral scholarship (Forschungsnetzwerk Alterssicherung - FNA). The views expressed here are solely of the authors. The usual disclaimer applies.

${ }^{\dagger}$ DIW Berlin, jgeyer@diw.de

${ }^{\ddagger}$ DIW Berlin, IZA Research Affiliate, cwelteke@diw.de
} 


\section{Introduction}

Population aging presents enormous challenges for public pension systems (OECD, 2015). Most OECD countries answered the challenges posed by increasing old-age dependency ratios by reforming their pension systems. A central aim of these reforms is to extend working lives alleviating the decline of the working age population (OECD, 2006, 2011). Reforms include increases in the early retirement age (ERA) and increases in the normal retirement age (NRA), i.e. the age at which people can first draw full benefits without actuarial deductions. Germany is characterized by a particularly steep increase in the old-age dependency ratio and low employment rates of older workers. In order to relieve public finances by increasing the employment rates of older workers, in a 1999 pension reform, Germany abolished an important early retirement program for women born after 1951. The reform effectively raised the ERA for women from age 60 to at least 63 . An increase in the retirement age has the potential to extend contribution periods and reduce the number of pension beneficiaries at the same time, if employment exits are successfully delayed. However, workers may not be able to work longer or may choose other social support programs as exit routes from employment. Large program substitution effects could undermine the potential positive fiscal effects of the pension reform. Therefore, it is important to empirically assess if an increase in the ERA induces increased inactivity or substitution into other government programs such as unemployment or disability benefits.

In this paper, we provide novel empirical evidence on this important research question. In more detail, we analyze the labor market effects of the substantial increase in the early retirement age for women. The change in ERA is a large negative wealth shocks for the affected cohorts. The reform provides a clean quasi-experimental setting as it induces a large one-time shift in the ERA. We exploit the unprecedented sharp discontinuity in the ERA between cohorts to estimate the causal impact on female employment behavior in a regression discontinuity framework based on high quality administrative data. We know the month of birth and compare women born close to the cutoff. Our research design allows us to quantify the causal effects of the reform on female employment, take-up of disability pensions, unemployment, and inactivity rates. Furthermore, we focus not only on the effects on levels, but also on employment outflows into other social security programs as a response to the reform. In contrast to most of the previous literature, we distinguish between active program substitution from employment into unemployment, disability pension or inactivity, and passive program substitution, which occurs due to continuance of the former status because an exit into early retirement is no longer attainable. Furthermore, we examine whether the behavioral reactions are heterogeneous across different groups. Raising the ERA might have undesired distributional effects as the ability to work longer and the remaining life expectancy may depend on socio-economic status. In particular, workers with poor health and a weak labor market position might be negatively affected by the reduced retirement options (Staubli, 2011).

We contribute to the literature in various ways. Similar to other studies, we exploit cohort-specific variation in incentives to retire (e.g., Mastrobuoni, 2009; Hanel and Riphahn, 2012; Cribb et al., 2014; Lalive and Staubli, 2014; Atalay and Barrett, 2015; Manoli and Weber, 2016; Engels et al., 2016). In contrast to previous studies, the reform we analyze is a large one-time change of pension rules. Usually changes of the retirement age are introduced in small steps over a longer time horizon, which generally requires stronger assumptions to separate the reform effect from time trends, other policy reforms, and cohort effects. Moreover, many studies focus on changes in the NRA, while only a few analyze the effect of changes in the ERA. Increasing the ERA implies that the choice set of older 
workers is reduced and that the employment reaction of those who would have chosen to retire depends on the relative attractiveness of the remaining options. There is a large literature that analyzing program substitution effects in the context of pension reforms (e.g., Duggan et al., 2007; Karlström et al., 2008; Li and Maestas, 2008; Coe and Haverstick, 2010; Staubli, 2011; Staubli and Zweimüller, 2013; Borghans et al., 2014; Atalay and Barrett, 2015; Inderbitzin et al., 2016). However, the existing evidence on the effectiveness of increasing the ERA and program substitution is mixed. Staubli and Zweimüller (2013) and Atalay and Barrett (2015) find that gradual increases in the ERA led to increased program substitution in Austria and Australia. In contrast, Manoli and Weber (2016) and Oguzoglu et al. (2016) do not find evidence for increased active substitution from employment into social security programs based on the same reforms.

Based on a linear regression-discontinuity design, we find that employment rates of women born in 1952 aged 60 and older increased markedly by 14.4 percentage points due to the reform. Interestingly, employment rates before age 60 remained unaffected by the reform, even though the reform was long anticipated. Although we find evidence for increased program substitution into unemployment, the increase in the unemployment rate is not due to active program substitution from employment but rather stems from the inability of unemployed women to retire early after the reform. We do not find evidence for increased unemployment, disability pension, or inactivity entry due to the ERA increase. Based on these results, we draw the following conclusions: First, the reform seems to be an effective tool to extend employment of employed women. Second, unemployed women remain longer in unemployment. Third, we do not find evidence for increased take-up of disability pensions. Fourth, the results suggests that the reform affected certain groups heterogeneously. We find larger positive effects on the employment rates of women with low income or poor health; however, the differences are statistically insignificant. We also find larger effects on unemployment rates in East Germany than in West Germany, which is consistent with the fact that unemployment rates were higher and early retirement was more prevalent in the East. Further heterogeneous effects of the reform result from the persistence of labor market statuses: Unemployed or inactive women remained in their respective status while employed women continued being employed. A tentative interpretation of these results is that the reform increased inequality within the affected cohorts.

The paper proceeds as follows: Section 2 briefly outlines the pension system and the 1999 pension reform. Section 3 derives hypotheses about potential behavioral reactions. Section 4 describes the administrative data that are used in our analysis. Section 5 describes our empirical strategy and Section 6 presents the results of the empirical analysis, including a discussion of the heterogeneity of the results across subgroups. Finally, Section 7 concludes.

\section{Institutional background}

In this section, we provide an overview of the German public pension system and its different early retirement programs. The 1999 pension reform, which this paper focuses on, is explained in detail. In addition, we discuss interactions of the pension system with other social security programs (unemployment and disability pensions) and highlight potential program substitution patterns. 


\subsection{The German public pension system}

The statutory public pension system covers most private and public sector employees. It provides old-age pensions, disability pensions, and survivors benefits. The system is financed by a pay-as-you-go (PAYG) scheme. The calculation of pension benefits is based on a point system that takes into account the entire earnings history and insurance record of each individual. A year's contribution at the average earnings of contributors earns one pension point. Moreover, pension points can be acquired during other insurance periods (e.g. unemployment, child raising and while providing informal care). Pensions are roughly proportional to an individual's average lifetime labor income and feature few redistributive properties. ${ }^{1}$

Depending on the length of the insurance record and other qualifying conditions, the age at which pension benefits can be claimed lies between 60 and 65.5 for the cohorts under study (1951-1952). In addition to the regular pension, which requires 5 years of contributions, until 2012 there were four early retirement programs with different qualifying conditions:

1. Pension for women

2. Invalidity pension

3. Pension after unemployment or old-age part-time work

4. Pension for the long-term insured

The first two of these programs allowed retirement starting from 60 years of age, the pension for women and the pension for people with severe disability status (invalidity pension). The NRA, the age at which full benefits can be claimed, was different between these programs. The NRA of the pension for women and for the invalidity pension was 65 and 63, respectively. Early retirement was associated with actuarial deductions of $0.3 \%$ per month before the NRA. That is, retiring through the pension for women at age 60 is associated with permanent pension deductions of $18 \%$. Deductions amount to $10.8 \%$ for people eligible for invalidity pensions. The other two early retirement programs allowed retirement starting from age 63. People who are not able to work due to severe health conditions can retire before the age of 60 through the disability pension program. See Table 4 for more details. ${ }^{2}$

\subsection{The 1999 pension reform}

The 1999 reform abolished the early retirement program for women in cohorts born after 1951. Effectively, the reform raised the earliest retirement age for most women to at least 63. Women born before 1952 could claim the pension for women if they fulfilled certain qualifying conditions. The eligibility criteria were: (i) at least 15 years of pension insurance

\footnotetext{
${ }^{1}$ Börsch-Supan and Wilke (2004) provide an extended overview of the German pension system.

${ }^{2}$ Note that the German pension system provides two different types of pensions due to impaired health. The disability pension ("Erwerbsminderungsrente") is similar to disability benefits in the US. Eligibility for full benefits requires that an individual is unable to work more than 3 hours a day for at least six months. Eligibility for partial disability benefits require that the individual is unable to work more than 6 hours a day. Eligibility requires 5 years of contributions. It is the only pension that is available before the age of 60 . In addition, there is a second type of old-age pension: the invalidity pension is available from age 60 for people with a severe disability status under German law. Invalidity status requires a degree of disability of $50 \%$ or more and does not require work incapacity. The ERA of this pension has been increased since 2012 (see Table 4).
} 
contributions; (ii) at least 10 years of pension insurance contributions after the age of 40 . These criteria ensured a minimum labor market attachment of eligible women. Our data show that about $60 \%$ of all women born in 1951 were eligible for the old-age pension for women. Take-up was particularly prevalent in East Germany, where most women have a strong labor market attachment and meet the qualifying conditions of this pension type. ${ }^{3}$

Due to the reform, women born in 1952 lose an important option to exit the labor market before age 63. At age 63, people with a long insurance record can retire with deductions. As explained above, the only remaining pension type before age 63 is the invalidity pension. However, even before the 1999 reform, if women had the the choice between the invalidity pension or the pension for women, the former implied lower deductions. In other words, invalidity pension has always been advantageous compared to the pension for women. Therefore, we do not expect large substitution into the invalidity pension due to the reform. For women born after 1951 who want to exit the labor market before age 63, the remaining options are unemployment benefits, disability pensions, or inactivity.

\subsection{Disability pension, unemployment insurance and inactivity}

It is theoretically plausible that some women who would have otherwise claimed old-age pension benefits chose another social support program or withdrew from the labor force. In the following, we briefly describe the design of unemployment insurance and disability pensions in Germany, focussing on the potential for interdependencies and program substitution.

Unemployment benefits in Germany replace about $60 \%$ of previous net earnings and increase pension entitlements. ${ }^{4}$ Eligibility and the entitlement period depend on the age and the previous working history. The maximum entitlement period for unemployment benefits did not change during our observation period. Specifically, the maximum entitlement period for individuals above the age of 57 was 24 months. Generally, there is a strong interdependence between unemployment benefits and pensions for older individuals. As documented in Grogger and Wunsch (2012), Giesecke and Kind (2013) and Engels et al. (2016), some older individuals use unemployment benefits as a bridge into retirement. In particular, there is evidence that unemployed individuals exhaust their full entitlement period for unemployment benefits before entering retirement. The design of the institution provides strong incentives for this behavior; unemployment benefits are relatively generous, periods in unemployment increase pension entitlements and, lastly, search requirements for unemployed persons close to retirement are very low. Therefore, an increase in the ERA is likely to affect the take-up of unemployment benefits in two ways: first, individuals have an increased incentive to postpone entry into unemployment, if unemployment benefits are indeed used as a pathway to retirement. This would lead to a shift in increased unemployment entry from 58 (cohort 1951) to 61 (cohort 1952) years; 24 months before reaching the cohort-specific ERA. Second, unemployment rates among 60 to 63 year-old women may increase due to program substitution because of the abolishment of the early retirement option, i.e. because women who want to exit employment between the old and new ERA must take another path to exit the labor market.

The disability pension (Erwerbsminderungsrente) is the only pathway to retirement before reaching the ERA. Eligibility requires the long-term (at least six months) inability to

\footnotetext{
${ }^{3}$ The pension due to unemployment or after old-age part-time work was abolished at the same time as the pension for women. However, this does not affect our analysis as the ERA for this pension type was already 63 .

${ }^{4}$ People receiving unemployment benefits acquire pension entitlements as if they earned $80 \%$ of their previous gross earnings.
} 
perform an activity under normal labor market conditions for at least six hours (partial disability pension) or at least three hours (full disability pension) per day. The pension is calculated based on the previous insurance biography and amounts to the pension that would be paid had the individual continued to work until she turned 60 . When reaching the statutory retirement age, the disability pension is converted into an old-age pension usually of the same level. In Germany, health-related eligibility criteria for disability pensions are relatively strict, especially sine a 2001 reform. About $40 \%$ of all applications are rejected. Therefore, using disability pensions as a pathway to a regular old-age pension is difficult and not typically an attractive option. Moreover, since 2001, actuarial deductions also apply to this type of pension. The pension is permanently reduced by $0.3 \%$ per month if retiring before the NRA. In 2012, the NRA of disability pensions was increased from 63 to 65 , with deductions capped at a maximum of $10.8 \%$. Virtually all of these pensions are reduced by maximum deductions since most people claim this pension before turning 60 (Deutsche Rentenversicherung, 2015, p.83).

Individuals who are neither eligible for disability pension nor unemployment benefits may choose inactivity, i.e. exit the labor force without benefit receipt. This is particularly relevant for women, who often are not the primary earner in their households.

\section{Expected reform effects}

The reform of 1999 is expected to have several effects on employment outcomes. We expect women born after 1951 to extend employment and to delay retirement entry compared to women unaffected by the reform. Since the reform did not just increase the penalty for early retirement but abolished the option altogether, we expect large effects on employment rates of wome aged 60 to 63 . However, not all women are able or willing to work until reaching the new ERA. Therefore, we expect increased program substitution, which is the response to similar reforms in other countries (see Staubli and Zweimüller, 2013; Atalay and Barrett, 2015).

Following Oguzoglu et al. (2016), we distinguish between two different kinds of effects: active and passive (mechanic) program substitution. Women who do not have an option to retire at 60, even though they would have retired in the absence of the 1999 reform, must divert into another employment status or continue their previous status. The continuation in a social security program due to the lack of a retirement option can lead to a passive increase in e.g. unemployment and inactivity rates. In contrast, active program substitution refers to flows from employment into other social security programs as a response to the elimination of the retirement option. In order to distinguish between passive and active program substitution, we analyze employment outflows into other social security programs around age 60 . There are mainly the two aforementioned social security programs that are relevant in this context: unemployment insurance and disability pensions (explained in detail in Section 2.3). As a third option, we consider potential increases in inactivity rates.

There are several reasons why we expect the 1999 reform to effect employment outcomes before the former ERA of 60. First, women born after 1951 who have a preference for early retirement around the age of 60 , may choose alternative pathways to exit employment, perhaps even before their $60^{\text {th }}$ birthday, instead of delaying until they reach the ERA. The ERA can serve as a reference age for retirement decisions (see Seibold, 2016), which leads to the bunching of retirement entries at the ERA, and a reduced number of exits among individuals approaching the reference age. Consequently, an ERA increase may lead to an increase in employment exits of women approaching age 60 . We refer to this effect as the 
reversed reference-age effect.

Second, women may bridge the last one or two years prior to reaching the ERA with unemployment. As explained in the previous section, German workers have an incentive to exit employment two years before reaching the ERA through unemployment benefits, which are paid for up to 24 months to older workers. An increase in the ERA leads to a shift in the bridge period. If women adjust their employment behavior and delay their (bridge into) retirement, we expect a negative effect on unemployment and disability pension rates for women approaching age 60, in particular among 58 and 59 year-old women. Instead we would expect women born after 1951 to enter unemployment at 61 or 62 years of age more often.

Third, the ERA increase was announced in 1999, while it only affected women turning 60 in 2012. Consequently, the ERA increase was known when the first affected cohort was 47 years old. It is not obvious a priori how younger women will adjust their labor supply in a response to the increased ERA. The reform can be interpreted as a strong negative wealth shock as it reduces the length of time that women receive pension benefits. Theoretically, this should have a positive effect on labor supply. If these women were forward looking, they might have adjusted labor supply as soon as the legislation was passed. ${ }^{5}$

\section{Data}

We use high-quality administrative data from public pension insurance accounts (VSKT: Versicherungskontenstichprobe). ${ }^{6}$ VSKT is a stratified random sample of all pension insurance accounts of people aged 30 to 67 . The VSKT is representative of the German population of public pension insurance accounts, if the appropriate sampling weights are used. Since the data are process-produced, recall errors due to memory gaps and wrong temporal assignment are avoided, while panel mortality is negligible (Fachinger and Himmelreicher, 2006). The data include the month of birth of each individual which allows to compare women born close to the cutoff. Furthermore, individual employment behavior and retirement entry is reported with monthly accuracy. A drawback is that socio-economic variables are only recorded to the extent that they are relevant for the calculation of pension benefits. Consequently, information on education is missing in about half of the cases. Information about occupations is only available for the last occupation at the time of data collection, which may not be representative of entire employment histories. Furthermore, it is not possible to link spouses and other household members within the data. ${ }^{7}$

For our analysis we use the VSKT of 2014 , the latest available wave at the time of

\footnotetext{
${ }^{5}$ We do not expect strong behavioral reactions to the changed incentives of the qualifying conditions. The eligibility criteria of the pension for women (namely after 15 years of pension contributions) are no longer relevant for cohorts born after 1951. However, early retirement at 63 requires the completion of a contribution period of 35 years, including child raising periods. It is not clear how the change in eligibility criteria for early retirement affects the labor supply of women between 47 and 59 . For example, a woman in the 1951 cohort with 14 years of contributions has a strong incentive to work at least one additional year to qualify for early retirement. The incentive to accumulate 35 contribution years is higher for cohorts born after 1951. The data show a large overlap between women who fulfill the criteria of the pension for women and those who fulfill the eligibility criteria for early retirement for the long-term insured. A graphic representation of the distribution of pension contribution years is in Appendix C.3. As documented in Seibold (2016) bunching around these thresholds is present, but it is very small and In fact, the vast majority of women who qualified for the pension for women were also eligible for long-term insured pension.

${ }^{6}$ We use the full VSKT, which is roughly four times as large as the scientific-use file SUFVSKT and can only be accessed on-site.

${ }^{7} \mathrm{~A}$ detailed description of the data can be found in Himmelreicher and Stegmann (2008).
} 
analysis. We restrict the sample to women born 12 months before and after the cutoff (cohorts 1951 and 1952). Furthermore, we exclude all women who paid contributions to a special miners' pension scheme (Knappschaftliche Versicherung) for at least one month, which applies to about $10 \%$ of all women. Another group excluded from our sample (about $6 \%$ of all women) consists of all women receiving an old-age invalidity pension at some point in their life. ${ }^{8}$ After dropping these groups, we are left with 7,365 women. ${ }^{9}$

The 1999 pension reform increases the ERA only for women who were eligible for the pension for women. Women who did not meet the qualifying conditions, are mot likely to be eligible to any early retirement program. In our analysis, we therefore focus on women who fulfill the eligibility criteria for the pension for women. ${ }^{10}$ Those criteria are the accumulation of at least 15 years of pension contributions, with 10 years after turning 40. About $60 \%$ of the women in our sample fulfill these eligibility criteria. Due to the traditionally stronger labor market attachment of women in East Germany, the share of eligible women amounts to more than $80 \%$ for East German women. Our final sample consists of 3,771 women who fulfill the eligibility criteria of the pension for women. About $30 \%$ of the eligible women in the sample (cohort 1951) retire early through the early pension for women before their $62^{\text {nd }}$ birthday.

The main variables of interest in this analysis are whether or not an individual is employed, unemployed, inactive, or receiving a disability pension at any given age in months. ${ }^{11}$ A woman counts as employed if she had a job which was subject to social security contributions or if she was marginally employed. ${ }^{12}$ The best approximation of inactivity is the residual category, which comprises all statuses that are not employment, unemployment, or pension receipt. The residual category includes periods of education or training, insured self-employment, non-commercial care for children or elderly family members, illness, and unknown status (missing value). By far the largest group within the residual category consists of women with missing employment status. We refer to the residual category as inactivity in the remainder of this paper. These women coule, in principle, be working as uninsured self-employed or as civil servants since these statuses are also recorded as missing values. However, this is very unlikely in the sample we select: women older than 58 who qualify for the pension for women. That is, women who paid 10 years social security contributions after their $40^{\text {th }}$ birthday. ${ }^{13}$

In order to analyze heterogeneous effects by income and health, we use information on average pension points and periods of sick-pay to approximate income groups and health

\footnotetext{
${ }^{8}$ As argued in Section 2.2, if women had the choice to either retire through the pension for women or the invalidity pension, the invalidity pension is always superior to the pension for women since it is associated with lower pension deductions. Therefore, we assume that the 1999 pension reform did not affect this group.

${ }^{9}$ We account for regional differences in the empirical analysis since the employment behavior of women in East and West Germany differs markedly. About 17\% of the sample collected most of their pension contribution points in East Germany. The assignment of a region to individual employment histories is straightforward because very few women in the relevant cohorts earned non-negligible pension points in both East and West Germany.

${ }^{10}$ We discuss potential bias due to sample selection in Appendix C.3. Furthermore, we include an analysis using a sample of all women regardless of pension eligibility in Appendix C.4.

${ }^{11}$ We define disability pension periods as months with pension receipt before reaching the ERA; and by using the pension-type information for current pension spells. If a disability pension is converted into an old-age pension, the months of old-age pension receipt are re-coded as disability pension periods.

${ }^{12}$ Marginal employment (geringfügige Beschäftigung) is defined as a tax-free employment-relationship with earnings under a certain threshold (until 2013 up to $400 € /$ month, since $2013450 € /$ month).

${ }^{13}$ Note that inactivity is used here to describe the status of out of the labor force and of the social security system. Therefore, it includes e.g. housework or care for a family member, which should not be misinterpreted as leisure or idleness.
} 
status. A women is defined to belong to the low income group if she is in the lowest third of the distribution of average pension points over all full contribution periods. ${ }^{14}$ The low income group is defined by having accumulated on average less than 0.52 annual pension points. That is equivalent to $52 \%$ of average earnings or 18,126 euro for a West German woman in $2014 .{ }^{15}$ Note that we use individual pension points, which are based on individual earnings. We approximated poor health using periods of sick-pay, which are only recorded if the sick leave exceeds six weeks or entails hospitalization for employed individuals. A person is defined as having a poor health status if she has at least one sick-pay spell between age 45 and 55, which holds true for about $26 \%$ of the sample of eligible women. ${ }^{16}$

\subsection{Descriptive evidence}

The distribution of employment status by age group is displayed in Figure 1 for the 1951 and 1952 cohorts. The employment rates of 58 and 59 year-old women are relatively high due to the sample restriction to women eligible for the pension for women. It shows that a large fraction $(26 \%)$ of women born in 1951 receive an old-age pension from their $60^{\text {th }}$ birthday onward. This fraction disappears if we look at the 1952 cohort, due to the ERA increase. Employment, unemployment, and inactivity rates increased for 60 and 61 yearold women born in 1952 (treatment group) compared to women born in 1951 (control group). In particular, the employment rate amounts to $70 \%$ in the cohort 1952, where it is $54 \%$ in the 1951 cohort.

Figure 1: Employment status by age group and cohort, sample of eligible women

Cohort 1951

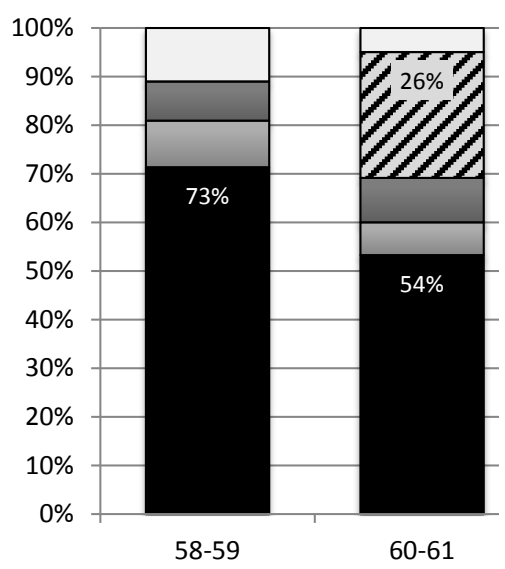

\section{Cohort 1952}

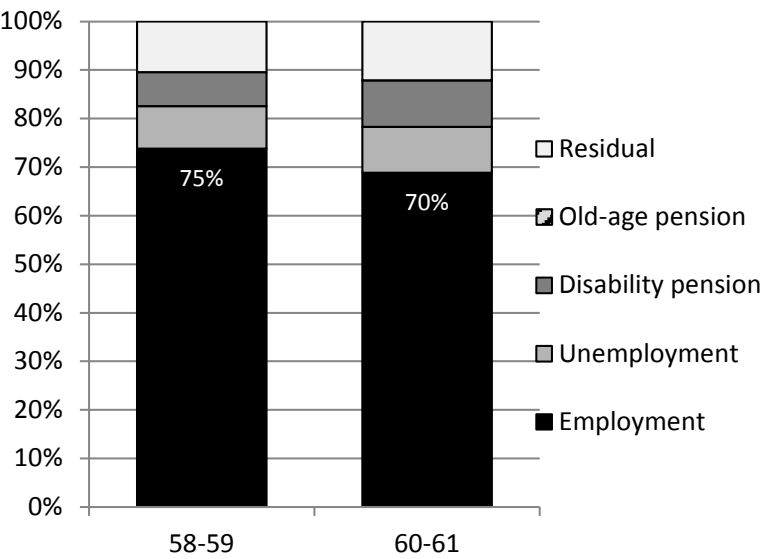

Source: VSKT 2014, own calculations

A closer look at the fractions of women in different employment status across age reveals that women born in 1951 exhibit a large drop in employment rates when reaching age 60,

\footnotetext{
${ }^{14}$ We used the pension points (avegpt) earned over full contribution periods only (byvl). Points earned in the East and West are treated equally; however, percentiles are constructed separately for East and West German women, using all women (not just eligible women).

${ }^{15} 18,126=0.52 \times 34,857$, where 34,857 was the average gross earnings of all insured individuals in West Germany in 2014.

${ }^{16}$ Employed women are more likely to receive sick-pay, therefore, the sub-sample of women with poor health is likely to be employed between 45 and 55 .
} 
while this discontinuity is not observed for the 1952 cohort (Figure 3a). Not surprisingly, the fraction of women receiving a pension (including disability pensions) increases sharply at the ERA for the 1951 cohort (Figure 3b). There is no visible difference in employment and retirement rates between cohorts before reaching age 60 .

Figure 2: Employment and pension recipient rates by age and cohort

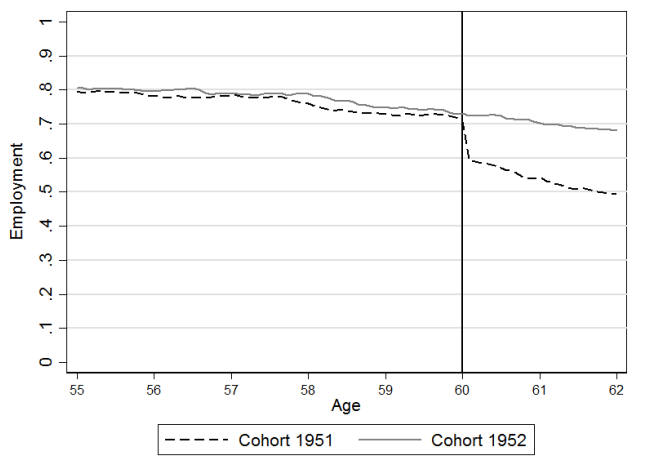

(a) Employment rate

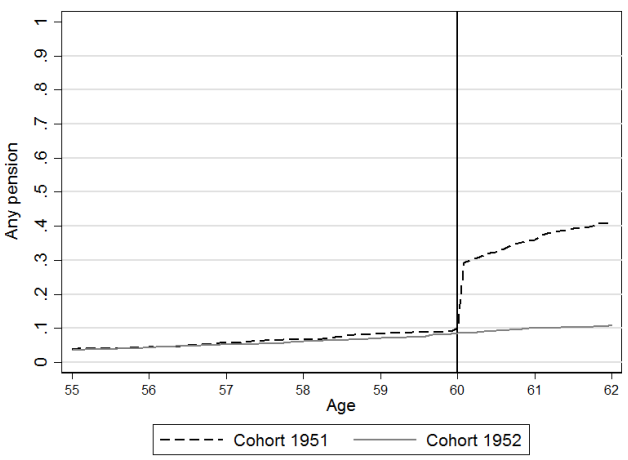

(b) Pension recipients

Notes: Employment includes marginal employment.

Source: VSKT 2014, own calculations

Figure 5a and Figure 5b show that the fraction of women in marginal employment and the unemployment rate are slightly higher for the 1952 cohort for all ages between 55 and 60 . At age 60 however, we observe a drop in marginal employment and unemployment rates of the 1951 cohort. From age 60 to 62 , the 1952 cohort is more likely to be marginally employed and unemployed. It can be seen in Figure $5 \mathrm{~d}$ that the fraction of inactive women also drops sharply when reaching age 60, indicating that a large share of women who were previously inactive start receiving the pension for women. The fraction of women receiving a disability pension increases continuously with age for both cohorts (Figure $5 \mathrm{c}$ ). It can also be observed that women born in 1951 are slightly more likely to receive a disability pension (Figure 5c), in particular between 57 and 61 years of age. Note that differences between cohorts and fluctuations over time can be due to e.g. time trends or macroeconomic shocks. However, our empirical identification strategy is not threatened as long as differences between cohorts are continuous over the month of birth (see Section 5 for a detailed description of our empirical strategy.)

While the sharp decrease in the proportion of women born in 1951 in several employment categories suggest an outflow into early retirement, an analysis of employment outflows is needed to gain further insights on employment exit behavior and potential program substitution effects. In particular, we cannot infer from Figure 4 whether the reform led to increased inflow into unemployment, disability pension, or inactivity from employment.

Employment outflows are displayed in Figure 7a to Figure 7d. The employment exit hazard rate is defined as the fraction of women exiting employment at age $t$, conditional on survival in employment (excluding marginal employment) up to age $t$, out of all women who were employed for at least six months when reaching age 58. Unemployment, disability pension, and inactivity entry rates are defined as the probabilities to enter the respective category conditional on having survived until $t$, and employment (including marginal employment) for at least six months at their $58^{\text {th }}$ birthday. Note that we do not condition on employment between age 58 and the first unemployment, disability pension or inactivity entry event. We only consider the first exit or entry, i.e. reentering the sample is not 
Figure 4: Employment status by age and cohort

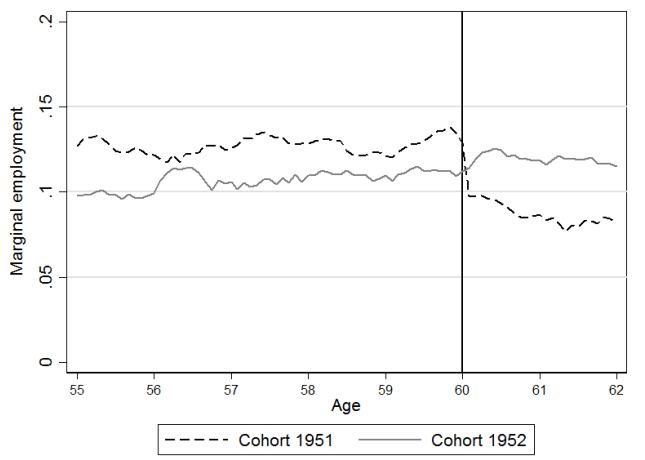

(a) Marginal employment

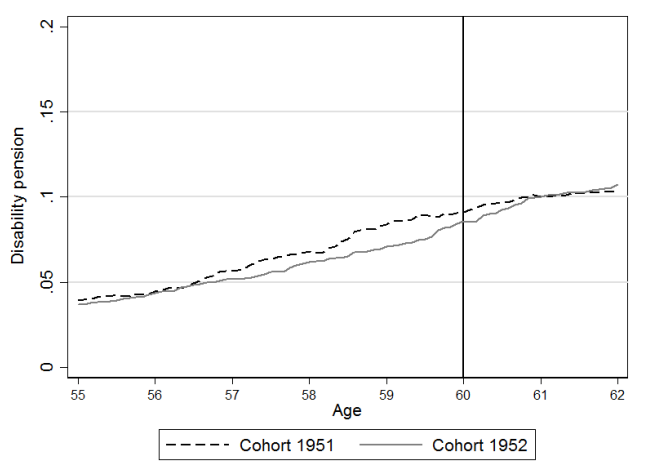

(c) Disability pension

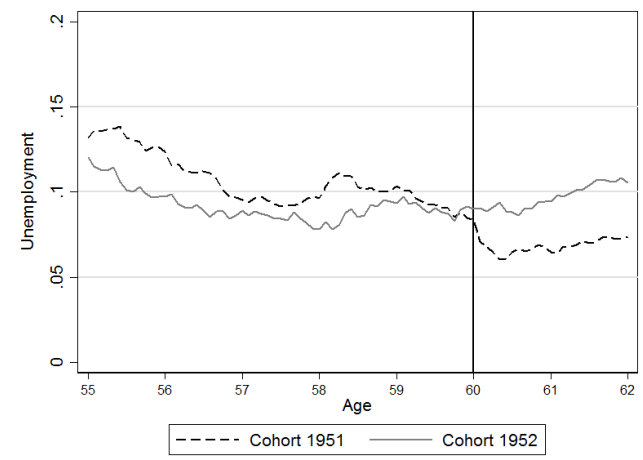

(b) Unemployment

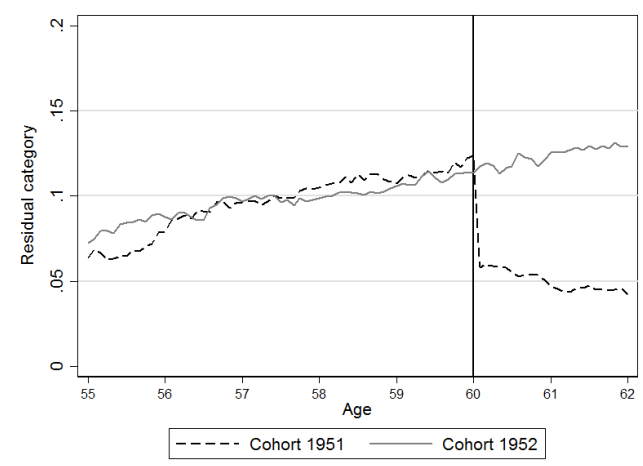

(d) Inactivity

Notes: The inactivity category combines all status except (marginal) employment, unemployment, old-age pension, or disability pension receipt.

Source: VSKT 2014, own calculations

possible. It can be seen in Figure 7 a that the employment exit hazard peaks at age 60 (one month after the $60^{\text {th }}$ birthday) and, to a lesser extent, at age 61 for the 1951 cohort, while the hazard remains flat for the 1952 cohort.

If women in our sample used 24 months of unemployment benefits receipt as a bridge to retirement, we would expect a peak in unemployment entry at age 58 for the 1951 cohort, and at age 61 for the 1952 cohort - or at least higher entry rates in the two years before reaching the ERA. With respect to active program substitution due to the pension reform, we expect increased entry into unemployment and disability for the 1952 cohort at around age 60 . However, neither are observed in Figure $7 \mathrm{~b}$. Therefore, it would be surprising if we discovered a large shift in unemployment entry or increased program substitution in the regression discontinuity analysis. The entry rates into disability pension and inactivity do not exhibit notable peaks, nor are there observable differences between cohorts (Figure 7c and Figure $7 \mathrm{~d})$.

These descriptive results suggest that there is not increased substitution from employment into unemployment, disability pension programs or inactivity due to the ERA increase. However, the hazard rates displayed here are descriptive only. At each age, the population that survives in employment is selective, based on previous hazard rates. Therefore, one cannot interpret the differences in hazard rates between cohorts in a causal sense. A more rigorous empirical analysis, described in the following section, is necessary to assess 
Figure 6: Employment exit and entry rates into other status by age and cohort

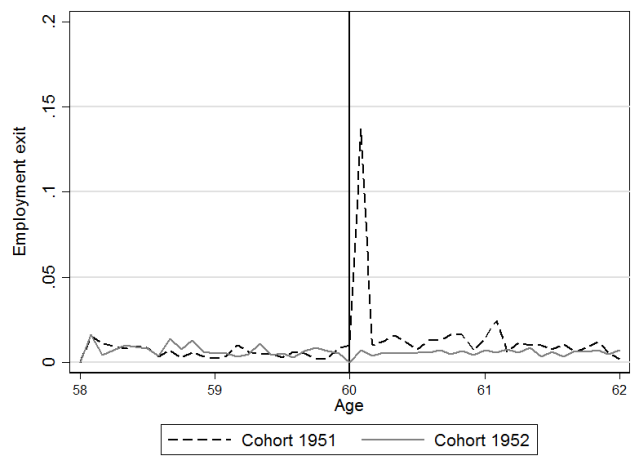

(a) Employment exit

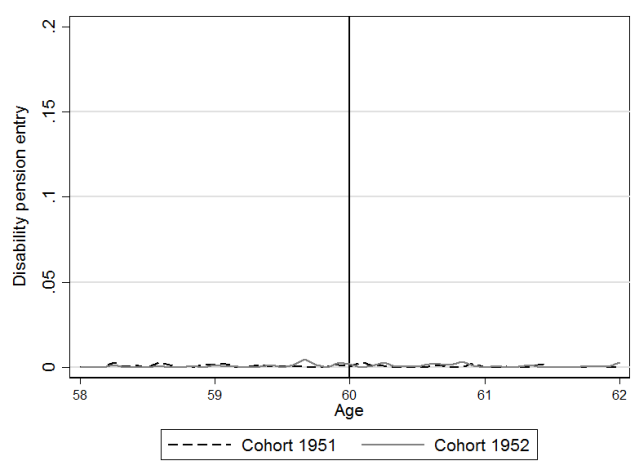

(c) Disability pension entry

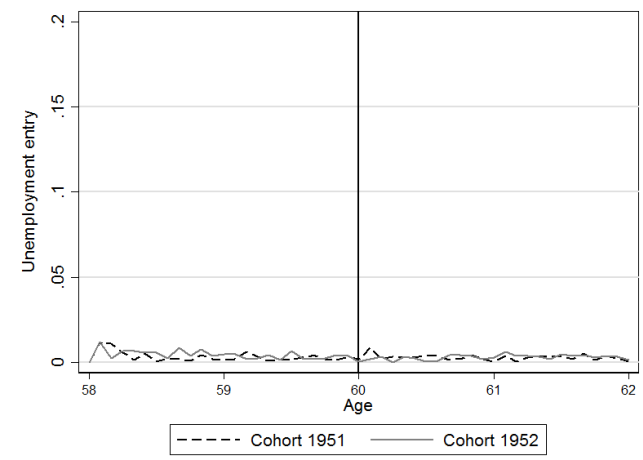

(b) Unemployment entry

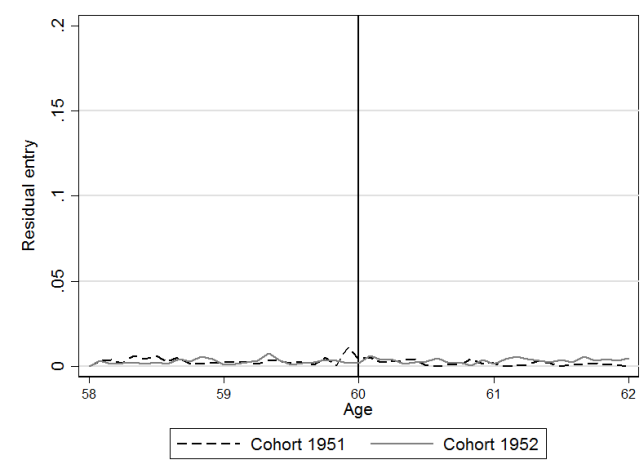

(d) Inactivity entry

Source: VSKT 2014, own calculations

whether the ERA increase led to extended employment and substitution into unemployment and disability pension programs or inactivity around the former ERA.

\section{Empirical strategy}

The empirical identification of the effect of pension eligibility rules on labor supply and retirement behavior is challenging: Employment histories and unobserved preferences for work and leisure affect both labor supply in old-age as well as eligibility for early retirement. One way to circumvent this endogeneity problem is to exploit exogenous variation in the pension system over time or cohorts due to policy changes. Our empirical strategy makes use of the 1999 pension reform, which eliminates the option to retire at age 60 for women born in 1952 and thereafter.

In the first part of our empirical analysis, we employ a linear regression discontinuity research design to estimate the causal effect of an increase in the ERA on employment rates, unemployment rates, the fraction of older women receiving a disability pension, and the fraction of inactive women. The regression discontinuity design solves the endogeneity problem by exploiting variation in the ERA by month of birth. It is valid, if we innocuously assume that labor supply at a given age would be continuous over the month of birth in absence of the 1999 reform.

The research design is implemented by the following empirical model: 


$$
y_{i t}=\alpha+\beta D_{i}+\gamma_{0} f\left(z_{i}-c\right)+\gamma_{1} D_{i} f\left(z_{i}-c\right)+X_{i t}^{\prime} \delta+\epsilon_{i t}
$$

Where the indicator $D_{i}=1$, if the individual was born after January 1952. The subscript $t$ refers to age in months and ranges from 721 to 744 (age 60 to 62 in monthly steps) in the baseline specification. The month of birth $z_{i}$ enters the empirical model in difference to the reform cutoff $c$, which is January 1952. In our baseline specifications, we include a linear trend in the running variable, $f\left(z_{i}-c\right)=z_{i}-c$. The specification allows for different slopes before and after the cutoff. All regressions include calendar month fixed effects, and dummies for three income groups, children, and region, summarized in $X_{i t}$. However, dropping $X_{i t}$ does not change the point estimates (see Appendix C.5 for regression results without covariates). Regression discontinuity analyses are naturally prone to model misspecification. A non-linearity in outcomes may falsely be interpreted as a discontinuity if it is unaccounted for. Therefore, we report linear regression results both with linear and quadratic trends in the running variable (RDD results with quadratic trends are displayed in Table 14 in Appendix C.6). Furthermore, we support our analysis by graphical analyses of local linear regression plots.

Employment status data is recorded for each individual at every age in months $t$. Therefore, we need to specify a time-window for the outcome variables of interest. In our baseline specification, we pool all observations from the month after the $58^{\text {th }}$ birthday to the $60^{\text {th }}$ birthday (age 58-59), and all observations from the month after the $60^{\text {th }}$ birthday to the $62^{\text {nd }}$ birthday (age 60-61). ${ }^{17}$ In order to account for correlation between observations for the same individual or individuals born in the same month, we cluster standard errors by month of birth. The baseline specification allows us to estimate treatment effects for four outcome variables for two age groups before and after age 60 . However, it may be of interest to estimate a more flexible model that allows for heterogeneous effects for every age in months $t$. Consequently, we analyze the reform effects for every age in months separately by including age-treatment interactions into our empirical model. The inclusion of age-dummies and interactions with the treatment variable $D_{i}=1$, allows us to interpret the coefficient of the interaction term as the reform effect on a specific age group (see Section 6.2).

In the second part of the empirical analysis, we focus on active program substitution due to the ERA reform (similar to Manoli and Weber (2016) or Oguzoglu et al. (2016)). In more detail, using a sub-sample of women who were employed on their $58^{\text {th }}$ birthday, we estimate outflows from employment, and inflows into unemployment benefits, disability pension, and inactivity (see Section 6.4). If we look at the effects on the shares in different employment categories only (as in Equation 1), we cannot distinguish between passive and active program substitution. In contrast, an analysis of employment outflows allows us to answer the question whether women increasingly used alternative social security programs to exit employment in response to the abolishment of the early retirement option. ${ }^{18} \mathrm{We}$ circumvented the dynamic selection problem by conditioning on employment at a fixed age in months. Formally, we estimate the same regression discontinuity model as described in Equation 1; however, the outcome of interest is the probability to exit employment (into unemployment or disability pension programs) within the following 2-4 years, conditional

\footnotetext{
${ }^{17}$ In order to have equal treatment and control groups, we do not include observations after their $62^{\text {nd }}$ birthday, which are only available for the older women in the sample.

${ }^{18} \mathrm{~A}$ drawback of survival data is that if one compares the hazard rates of two groups over time, the group composition changes if one group has a higher exit probability. This is called the dynamic selection problem. Consequently, we cannot estimate treatment effects by comparing the difference in hazard rates between cohorts over age in months.
} 
on employment for at least six months at the 58th birthday. Conditioning on employment at certain age is problematic if it is itself an outcome that is potentially affected by the reform. However, we can show that there is no discontinuity in the employment rate at the sample entry age of 58 (Figure 12 in Section 6.4). Consequently, we argue that treatment effects on flow variables can consistently be estimated using the linear RD approach described above.

\subsection{Threats to identification}

The RD design is only valid if women cannot manipulate the treatment assignment variable (Lee and Lemieux, 2010), which is the month of birth in our research design. Evidently, it is impossible that women or their parents manipulated the date of birth in anticipation of the policy change, as the reform was introduced long after the cohorts in question were born. Furthermore, we are not aware of any discontinuous changes in the incentive to give birth in December 1951 as opposed to January $1952 .{ }^{19}$

One of the most important assumptions of our analysis is that any discontinuities in the outcome variables at the cutoff are solely due to the 1999 pension reform. In particular, we need to assume that the differences between the cohorts in question are not caused by other policy changes. Two other pension policy changes also became effective for individuals born after January 1st, 1952. First, the old-age pension for the unemployed was abolished for all individuals born after 1951 as part of the 1999 pension reform. However, the ERA for this pension was already at 63 . Therefore, this change did not affect women at age 60. Second, the ERA of the invalidity pension program was increased from 60 to 63 in monthly steps starting with individuals born in January 1952. We exclude all women who received an invalidity pension because the ERA for the invalidity pension was also changed for the same cohorts as for the pension for women. It can be assumed that women eligible for either pension will choose the invalidity pension due to the significantly more generous pension benefits.

Even in the absence of other reform changes, women born in 1952 may still be different from women born earlier due to time trends in employment outcomes. Employment rates of women have been increasing over the past decades for every age. Including linear or quadratic trends in birth-dates should resolve this issue in an RD research design, as long as we can assume that women who were born close to the cutoff are not different from each other. This is tested by checking for discontinuities in covariates, using the same regression discontinuity framework. Results from the test for covariate discontinuities are displayed in Table 7 in Appendix C.1. We do not find significant discontinuities in covariates that are not inherently influenced by the 1999 reform. Furthermore, we perform a differencein-discontinuities analysis in order to test whether our results are caused by a turn of the year effect. Reassuringly, the results of the difference-in-discontinuity analysis, displayed in Table 8 and Table 9 in Appendix C.2, do not differ significantly from our baseline results.

A possible concern arises due to the selection of the sample by the eligibility criteria of the pension for women. Specifically, women born in 1951 may select into the sample by extending their pension contribution period in order to be eligible for early retirement. In contrast, women born in 1952 do not have the same incentives to fulfill the eligibility criteria. We discuss the problem of sample selectivity in Appendix C.3. We show that the potential bias due to selection is negligible because there was no change in the fraction fulfilling early retirement eligibility criteria due to the reform. We repeat the analysis without sample restrictions using all women born 1951 and 1952 regardless of pension eligibility

\footnotetext{
${ }^{19}$ It can be shown that the number of observations is relatively stable across all months of birth.
} 
criteria. We find that the pattern of the reform effects is very similar when including the non-eligible women yet effects are at a lower level. The results are in Appendix C.4.

\section{Results}

\subsection{Baseline results}

The results of the linear regression discontinuity analysis are displayed in Table 1. Figure 9a to 9d visualize the results using local linear regression on both sides of the cutoff, a triangular kernel, and a bandwidth of 12 months.

The increase in the ERA had an average positive effect of 14.4 percentage points on the employment rate of 60 and 61 year-old women (see Column 1, Table 1). The coefficients can be interpreted as the average percentage point change in employment rates of all women in this age group due to the pension reform. Compared to the pre-reform mean the relative increase amounts to more than $26 \%$. The fraction of women receiving a pension mechanically dropped by 25 percentage points to zero (Column 5). About $58 \%$ of those women, who would have retired if they had the option, continue to work due to the reform. The remaining women split equally in unemployment and inactivity.

In addition to the effects on employment rates, we estimate the effects of the ERA increase on the unemployment rate (Column 2), the fraction of women receiving a disability pension (Column 3), and the fraction of inactive women (Column 4). The unemployment rate and the fraction of women in the inactive category increased significantly by 5.2 percentage points on average due to the ERA increase. The positive effect on the unemployment rate can be due to either a passive increase in the unemployment rate or an active program substitution from employment into unemployment. The zero effect on disability pension participation rates suggests that there is not program substitution into the disability pension program. i.e. the disability pension program is not used as an alternative pathway to enter retirement.

Our results suggest that the linear trend in month of birth does not affect the outcome on either side of the cutoff. Whether or not a woman has children does not affect the outcome significantly. Women in West Germany are more likely to be employed, to receive a disability pension, or to be inactive, while East German women are more likely to be unemployed. Note that the results do not change if we drop all covariates (see Table 12 Appendix C.5). Including a quadratic function of month of birth does not alter the result considerably (see Table 14 in Appendix C.6). 
Table 1: Linear regression results, age 60-61

\begin{tabular}{lccccc}
\hline & $\begin{array}{c}(1) \\
\text { Employment }\end{array}$ & $\begin{array}{c}(2) \\
\text { Unemployment }\end{array}$ & $\begin{array}{c}(3) \\
\text { Disability }\end{array}$ & $\begin{array}{c}(4) \\
\text { Inactivity }\end{array}$ & $\begin{array}{c}(5) \\
\text { Pension }\end{array}$ \\
\hline$D_{i}$ & $0.144^{* * *}$ & $0.052^{* * *}$ & -0.004 & $0.052^{* * *}$ & $-0.249^{* * *}$ \\
Month of birth & $(0.0271)$ & $(0.0111)$ & $(0.0232)$ & $(0.0123)$ & $(0.0270)$ \\
& 0.002 & -0.002 & -0.001 & 0.001 & -0.001 \\
$D_{i} \times$ Month of birth & $(0.0029)$ & $(0.0013)$ & $(0.0020)$ & $(0.0010)$ & $(0.0026)$ \\
& -0.003 & 0.001 & 0.003 & 0.001 & 0.003 \\
Children & $(0.0040)$ & $(0.0016)$ & $(0.0029)$ & $(0.0018)$ & $(0.0033)$ \\
\multirow{3}{*}{ West } & 0.010 & -0.013 & -0.006 & -0.017 & 0.000 \\
\multirow{2}{*}{ Constant } & $(0.0164)$ & $(0.0119)$ & $(0.0132)$ & $(0.0128)$ & $(0.0142)$ \\
& $0.051^{* *}$ & $-0.067^{* * *}$ & $0.022^{*}$ & $0.029^{* *}$ & -0.018 \\
N & $(0.0206)$ & $(0.0125)$ & $(0.0109)$ & $(0.0114)$ & $(0.0161)$ \\
$R^{2}$ & $0.380^{* * *}$ & $0.181^{* * *}$ & $0.117^{* * *}$ & $0.074^{* * *}$ & $0.409^{* * *}$ \\
\hline Pre-treatment mean & $(0.0328)$ & $(0.0167)$ & $(0.0278)$ & $(0.0206)$ & $(0.0379)$ \\
\hline
\end{tabular}

Notes: Robust standard errors in parentheses. Significance levels: *** $\mathrm{p}<0.01$, ** $\mathrm{p}<0.05$, * $\mathrm{p}<0.1$. All linear regressions include calendar month fixed effects, income group dummies, and linear trends in the running variable (month of birth) on both sides of the policy cutoff. Standard errors are clustered by month of birth.

Source: VSKT 2014, own calculations

Figure 8: Local linear regression plots, age 60-61

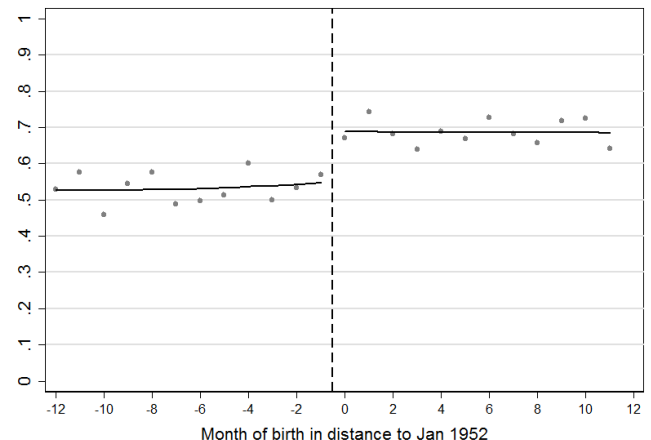

(a) Employment

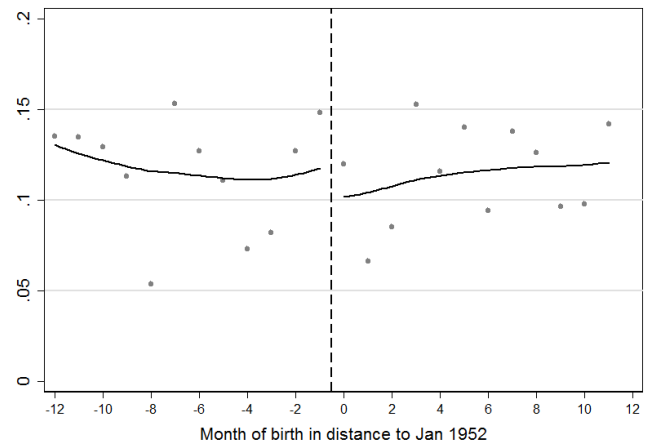

(c) Disability pension

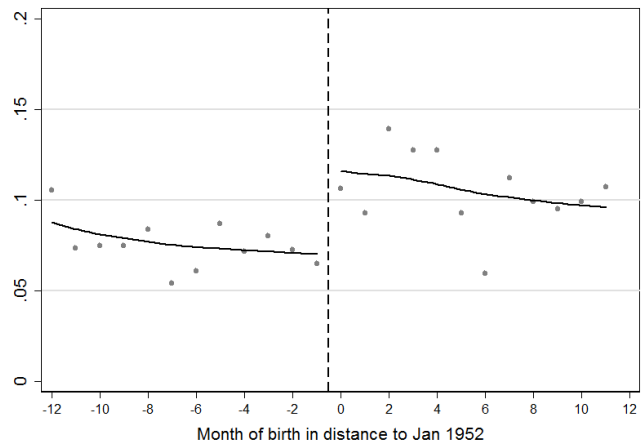

(b) Unemployment

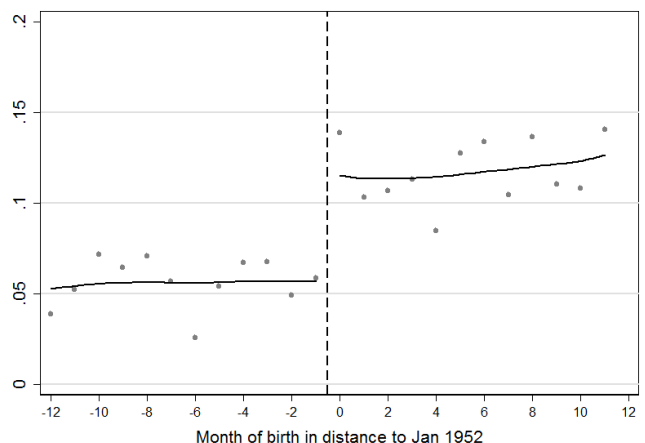

(d) Inactivity

Notes: Scatter plots display mean outcome values using monthly bins. Local linear regression plots are based on triangular kernel functions with a bandwidth of 12 months.

Source: VSKT 2014, own calculations 


\subsection{Effects across the age profile}

In order to shed more light on the effects of an ERA increase on employment outcomes at different ages, we interact the entire age profile (in months) with the right hand side of our regression equation. Thereby, we allow for heterogeneous treatment effects by age in months. The resulting coefficients by age in months are displayed in Figure 11a to Figure 11d. The results suggest the effect on employment rates of 60 to 62 year old women is positive and increasing with age. The gradual increase after age 60 is due to pre-reform pension entry past age 60 . As expected, we can observe a positive effect on unemployment and inactivity rates from age 60 onward due to the elimination of the option to retire early. Our results suggest that the fraction of women receiving a disability pension did not increase for any age-group.

There are several reasons why we expect the ERA increase to have an effect on employment outcomes before the former ERA of 60 (see Section 3). The results of our baseline linear regression analysis on employment outcomes of 58 and 59 year-old women are displayed in Table 5 in Appendix B. As described in Section 3, we expect a decrease in the unemployment rate of 58 to 60 year-old women and an increase in unemployment rates for 61 year-old women, if women are bridging the last 24 months before retirement entry with unemployment benefits. However, we do not find evidence for bridging behavior (Figure 11b). The pooled regression for women aged 58 and 59, displayed in Table 5, confirms that there is no significant increase in unemployment rates for this age group. However, we can see in Figure 11b that there is a small positive effect on the unemployment rate of some age-groups approaching age 60 , which is consistent with a reversed reference age effect.

Furthermore, we do not find evidence for cohort differences in employment and inactivity rates before age 60, as shown in Figures 11a, and Figure 11d. We conclude that, even though the ERA increase was long anticipated, there was little or no adjustment in labor supply in anticipation of the ERA increase. 
Figure 10: Coefficients of ERA increase by age in months

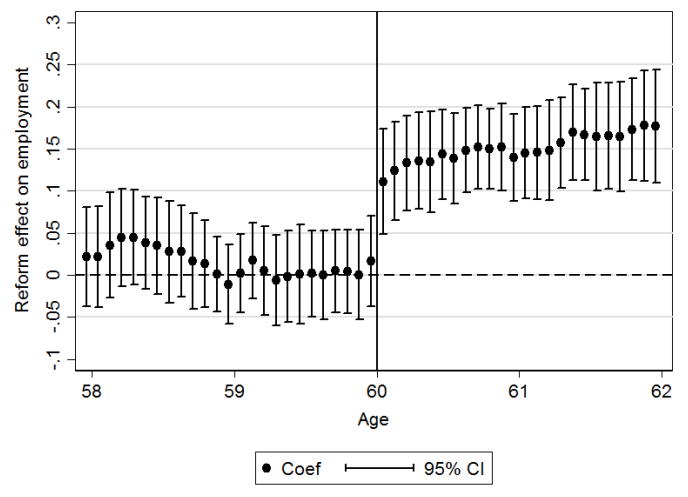

(a) Employment

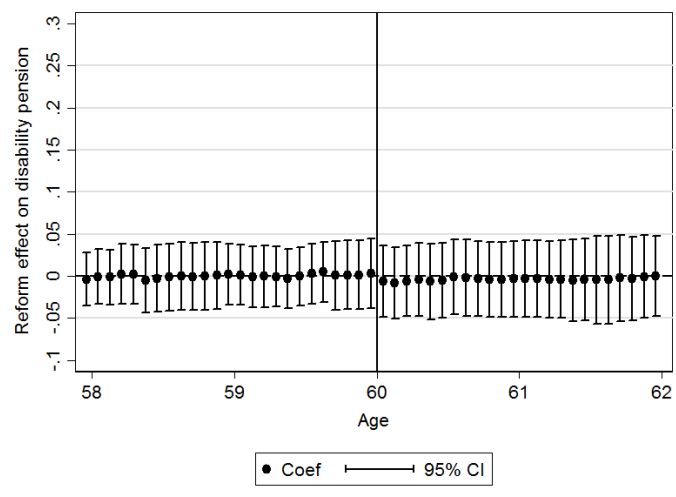

(c) Disability pension

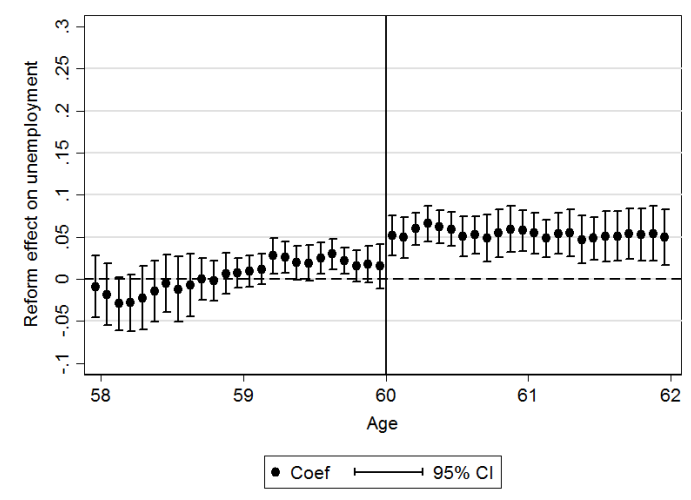

(b) Unemployment

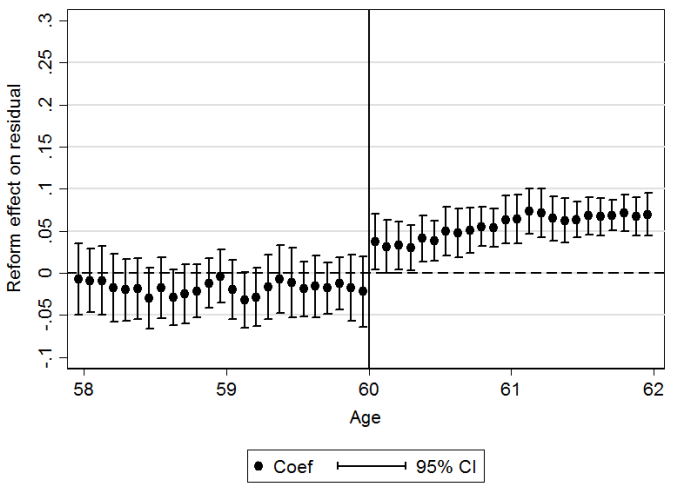

(d) Inactivity

Notes: The coefficients of the treatment dummy interacted with the age profile are estimated using a linear regression model including age fixed effects, linear trends in month of birth and the interaction with age in months, calendar month fixed effects, income groups, and a dummy for West Germany. Confidence intervals of clustered standard errors are displayed using error bars.

Source: VSKT 2014, own calculations

\subsection{Effect heterogeneity by subgroups}

In order to understand the impact of the ERA increase, it is necessary to learn more about the group affected by the reform. A comparison of women who retire early with those who retire with 62 or later, displayed in Table 16 in Appendix D, provides insights on the characteristics of the group affected by the pension reform. Women who retire early have fewer pension points on average, i.e. lower average earnings. The sum of pension points, contribution points after age 40, and the total contribution period are also lower for early retirees, which is not surprising due to the shorter working lifetime. Furthermore, women who retire early are more likely to have poor health. Women who retire late are more likely to be employed and less likely to be unemployed when they reach age 60 .

If women who make use of the early retirement option differ from those working longer, we expect the abolishment of the early pension for women to have heterogeneous effects on different subgroups. Therefore, we split our sample into several sub-samples to evaluate whether the reform had heterogeneous effects. In particular, we distinguish between East and West Germany. ${ }^{20}$ Furthermore, we distinguish women with low income, poor health

\footnotetext{
${ }^{20} \mathrm{~A}$ woman is defined as West German if she collected the majority of her pension contribution points in
} 
and women with and without children. ${ }^{21}$

The results for the analysis of different subgroups are displayed in Table 2 (and Table 6 in Appendix B for 58-59 year-old women). Women in East Germany are much more likely to be eligible for the woman's pension. Consequently, we find larger, although not significantly, employment effects for East Germany than for West Germany. While the reform effect on unemployment rates of 60 and 61 year-old women is negligible in West Germany, there is a large positive effect of about 15 percentage points on the unemployment rate of women in East Germany. This is likely to be due to larger overall unemployment rates in the East.

Table 2: Subgroup analysis - linear regression results, age 60-61

\begin{tabular}{lccccc}
\hline & $(1)$ & $(2)$ & $(3)$ & $(4)$ & \\
& Employment & Unemployment & Disability pension & Inactivity & $\mathrm{N}$ \\
\hline Baseline & $0.144^{* * *}$ & $0.052^{* * *}$ & -0.004 & $0.052^{* * *}$ & 3771 \\
& $(0.0271)$ & $(0.0111)$ & $(0.0232)$ & $(0.0123)$ & \\
West Germany & $0.124^{* * *}$ & 0.015 & 0.007 & $0.062^{* * *}$ & 2727 \\
& $(0.0430)$ & $(0.0147)$ & $(0.0283)$ & $(0.0197)$ & \\
East Germany & $0.184^{* *}$ & $0.149^{* * *}$ & -0.028 & 0.026 & 1044 \\
& $(0.0675)$ & $(0.0375)$ & $(0.0381)$ & $(0.0212)$ & \\
Low income & $0.178^{* * *}$ & 0.028 & -0.032 & $0.067^{* *}$ & 1046 \\
Poor health & $(0.0443)$ & $(0.0251)$ & $(0.0304)$ & $(0.0310)$ & \\
& $0.159^{* * *}$ & $0.045^{* *}$ & -0.008 & $0.051^{*}$ & 988 \\
Children & $(0.0512)$ & $(0.0206)$ & $(0.0669)$ & $(0.0252)$ & \\
& $0.144^{* * *}$ & $0.053^{* * *}$ & 0.005 & $0.042^{* *}$ & 3198 \\
No children & $(0.0274)$ & $(0.0140)$ & $(0.0245)$ & $(0.0156)$ & \\
& $0.152^{* * *}$ & 0.039 & -0.075 & $0.099^{* * *}$ & 573 \\
& $(0.0446)$ & $(0.0308)$ & $(0.0472)$ & $(0.0291)$ & \\
\hline
\end{tabular}

Notes: Robust standard errors in parentheses. Significance levels: *** $\mathrm{p}<0.01, * * \mathrm{p}<0.05, * \mathrm{p}<0.1$. All linear regressions include calendar month fixed effects, income group dummies, and linear trends in the running variable (month of birth) on both sides of the policy cutoff. Standard errors are clustered by month of birth.

Source: VSKT2014, own calculations

We expect women to suffer disproportionately by an ERA increase, if they have a stronger preference to retire early than the average population. Retirement incentives with respect to income groups are not unambiguous due to income and substitution effects. We find slightly larger effects on employment rates for the sub-group of women with low average earnings. We do not find a significant increase in unemployment for this group.

Women with poor health can be expected to have strong preferences for early retirement and inelastic labor supply at high ages. Consequently, we expect women with poor health to shirk into alternative employment-exit paths when the ERA is increased. In particular, we expect larger unemployment rates and an increase in disability pension participation rates. Our results show that the disability pension rates did not increase for any subgroup as a response to the ERA reform. Among women without children, the effect on inactivity rates is larger than for the whole sample including women with children.

Overall, we conclude that the ERA increase affected certain groups heterogeneously. Women in East Germany are more affected than women in the West. In particular, un-

West Germany.

${ }^{21}$ Low income is defined by the lowest third of the distribution of pension points collected in full contribution periods. Poor health is defined as having at least one sick-pay spell from age 45 to age 55 . Note that women who received sick pay are more likely to be employed or unemployed than inactive. Due to data limitations, we cannot divide the sample into married and unmarried women, even though this would be another sub-group analysis of interest. 
employment rates of 60 to 62 year-old women increase more in East than West Germany. Furthermore, we find suggestive evidence for slightly higher employment effects for 60 and 61 year-old women with low income, poor health and women without children.

\subsection{Employment outflows and program substitution}

The results described in the previous sections suggest that the ERA increase led to increased program substitution into unemployment. Furthermore, we find evidence for increased inactivity of 60 to 62 year-old women as a response to the reform. This could be caused by passive (women remain in their respective labor market status) or active substitution from employment into unemployment or inactivity because women are not willing or able to work until the new ERA. In order to distinguish between passive and active program substitution, we estimate the effect of the ERA increase on the probability to exit employment (and enter unemployment, disability pension program, or residual category) in a specific age window, conditional on employment for at least 6 months at the start of this window. In particular, we condition on employment for at least 6 months at the $58^{\text {th }}$ birthday and estimate the effects on the probability to exit employment in the following two and four years. For identification of the treatment effect, we have to assume that employment rates at age 58 are unaffected by the reform. A test of discontinuity in the employment rate at the $58^{\text {th }}$ birthday is displayed in Figure 12. There is no statistically significant discontinuity in the employment rate at the cutoff. ${ }^{22}$

Figure 12: Test for discontinuity in employment rate at $58^{\text {th }}$ birthday

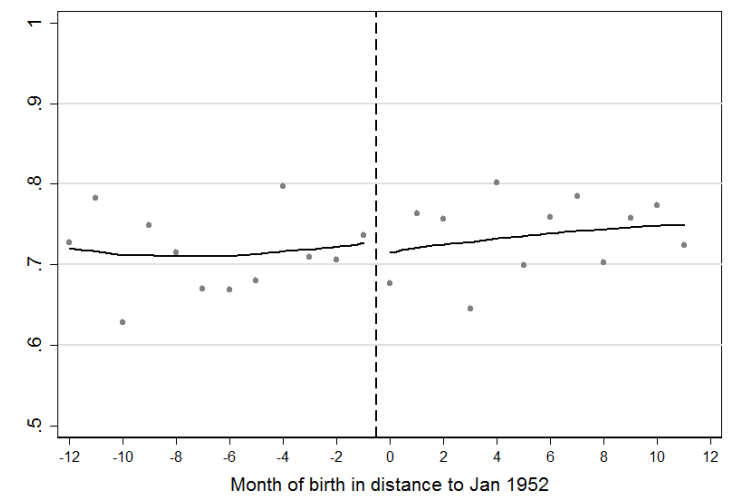

Notes: The scatter plot displays mean outcome values using monthly bins. The local linear regression plot is based on triangular kernel functions with a bandwidth of 12 months.

Source: VSKT2014, own calculations

The results for the employment outflow analysis are displayed in Table 3, where the coefficients in the odd columns can be interpreted as the reform effect on the probability to exit/enter the respective category between the $58^{\text {th }}$ and the $60^{\text {th }}$ birthday. The coefficients in the even columns correspond to the effects on the probability to exit/enter the respective categories in the four years between the $58^{t h}$ and the $62^{\text {nd }}$ birthday. We find a large negative effect of 21 percentage points on the probability to exit employment between age 58 and 62 , which is solely due to decreased exit rates between 60 and 62 . Furthermore, we find small positive effects on unemployment, disability pension and inactivity entry rates of 58 and 59 year-old women who were employed at their $58^{\text {th }}$ birthday. This could be explained

\footnotetext{
${ }^{22}$ This is supported by a regression analysis that is not reported here.
} 
by a small reversed reference age effect, i.e. by a lack of entries in these categories in the 1951 cohort. However, the effects are small and only significant at the $10 \%$ level. The lack of any increase in program entry for women aged 60 to 62 suggests that there the ERA increase did not lead to increased active program substitution.

Table 3: Effects on employment outflows, conditional on employment with age 58

\begin{tabular}{|c|c|c|c|c|c|c|c|c|}
\hline & (1) & $(2)$ & (3) & (4) & $(5)$ & (6) & $(7)$ & (8) \\
\hline Outcome & \multicolumn{2}{|c|}{ Employment exit } & \multicolumn{2}{|c|}{ Unemployment entry } & \multicolumn{2}{|c|}{ Disability entry } & \multicolumn{2}{|c|}{ Inactivity entry } \\
\hline Age window & $58-59$ & $58-61$ & $58-59$ & $58-61$ & $58-59$ & $58-61$ & $58-59$ & $58-61$ \\
\hline$D_{i}$ & $\begin{array}{c}0.013 \\
(0.0189)\end{array}$ & $\begin{array}{c}-0.206^{* * *} \\
(0.0442)\end{array}$ & $\begin{array}{c}0.028^{*} \\
(0.0136)\end{array}$ & $\begin{array}{c}0.023 \\
(0.0209)\end{array}$ & $\begin{array}{c}0.011^{*} \\
(0.0063)\end{array}$ & $\begin{array}{c}0.015 \\
(0.0145)\end{array}$ & $\begin{array}{c}0.028^{*} \\
(0.0136)\end{array}$ & $\begin{array}{c}0.023 \\
(0.0209)\end{array}$ \\
\hline Month of birth & $\begin{array}{c}0.002 \\
(0.0021)\end{array}$ & $\begin{array}{c}0.006 \\
(0.0037)\end{array}$ & $\begin{array}{c}0.001 \\
(0.0010)\end{array}$ & $\begin{array}{c}-0.000 \\
(0.0007)\end{array}$ & $\begin{array}{l}-0.002^{* *} \\
(0.0009)\end{array}$ & $\begin{array}{c}-0.001 \\
(0.0014)\end{array}$ & $\begin{array}{c}0.001 \\
(0.0010)\end{array}$ & $\begin{array}{c}-0.000 \\
(0.0007)\end{array}$ \\
\hline$D_{i} \times$ Month of birth & $\begin{array}{c}-0.003 \\
(0.0025)\end{array}$ & $\begin{array}{c}-0.000 \\
(0.0056)\end{array}$ & $\begin{array}{c}-0.002 \\
(0.0017)\end{array}$ & $\begin{array}{c}0.003 \\
(0.0033)\end{array}$ & $\begin{array}{c}0.002^{*} \\
(0.0011)\end{array}$ & $\begin{array}{c}0.002 \\
(0.0024)\end{array}$ & $\begin{array}{c}-0.002 \\
(0.0017)\end{array}$ & $\begin{array}{c}0.003 \\
(0.0033)\end{array}$ \\
\hline West & $\begin{array}{l}-0.021 \\
(0.0154)\end{array}$ & $\begin{array}{c}-0.064 * * * \\
(0.0168)\end{array}$ & $\begin{array}{c}-0.051 * * * \\
(0.0130)\end{array}$ & $\begin{array}{c}-0.068 * * * \\
(0.0169)\end{array}$ & $\begin{array}{c}-0.009 \\
(0.0055)\end{array}$ & $\begin{array}{c}-0.009 \\
(0.0078)\end{array}$ & $\begin{array}{c}-0.051^{* * *} \\
(0.0130)\end{array}$ & $\begin{array}{c}-0.068^{* * *} \\
(0.0169)\end{array}$ \\
\hline Constant & $\begin{array}{c}0.258^{* * *} \\
(0.0202)\end{array}$ & $\begin{array}{c}0.640 * * * \\
(0.0397)\end{array}$ & $\begin{array}{l}0.154^{* * *} \\
(0.0155)\end{array}$ & $\begin{array}{l}0.238 * * * \\
(0.0159)\end{array}$ & $\begin{array}{l}0.016^{* *} \\
(0.0069)\end{array}$ & $\begin{array}{c}0.041^{* * *} \\
(0.0101)\end{array}$ & $\begin{array}{c}0.154^{* * *} \\
(0.0155)\end{array}$ & $\begin{array}{c}0.238 * * * \\
(0.0159)\end{array}$ \\
\hline Observations & 2,447 & 2,447 & 2,732 & 2,732 & 2,732 & 2,732 & 2,732 & 2,732 \\
\hline
\end{tabular}

Notes: Robust standard errors in parentheses. Significance levels: *** $\mathrm{p}<0.01$, ** $\mathrm{p}<0.05$, * $\mathrm{p}<0.1$. All linear regressions include calendar month fixed effects, income group dummies, and linear trends in the running variable (month of birth) on both sides of the policy cutoff. Standard errors are clustered by month of birth.

Source: VSKT 2014, own calculations

\section{Conclusion}

This paper provides novel insights about the causal effects of pension reforms on labor market outcomes. We exploit a large exogenous increase in the ERA for women. In more detail, we focus on the 1999 pension reform that increased the ERA by at least three years for women born after December 1951. Previous studies show that labor market exits increase significantly at the pension eligibility age. If women shift their employment exit to the new ERA, it might be an effective tool to increase old-age employment. However, it could imply that some women who are not able to extend their working life are adversely affected by this reform. The estimation is based on high-quality administrative data from the German pension insurance.

The sharp discontinuity in the ERA by cohorts allows us to analyze the behavioral responses using a regression discontinuity design. Our results show that employment rates among women between the old and new ERA increased by 14.4 percentage points - which corresponds to an increase of about $26 \%$ compared to the pre-reform employment rate. Employment rates before age 60 remain unaffected by the reform, even though the reform was long anticipated. This is also surprising since previous studies show that earlier cohorts often used unemployment benefits as a bridge to retirement.

Furthermore, we find a positive reform effect on the unemployment and inactivity rates rate of 60 to 62 year-old women, which is caused by passive rather than active program substitution. That is, women who lost the early retirement option remained in their respective labor market status, i.e. in unemployment or inactivity, instead of retiring early. In order to distinguish between passive and active program substitution, we analyze the effects on employment outflows, and unemployment and disability pension inflows. We do not find increased unemployment, inactivity or disability pension entry among 60 to 
62 year-old women. In other words, unemployed or inactive women did not return on the labor market. Employed women of the 1952 cohort remained in employment.

The ERA increase might have undesired heterogeneous effects as the ability to work long and the remaining life expectancy may depend on socio-economic status. In particular, workers with poor health and weak labor market position might be negatively affected by fewer retirement options. Consequently, we examine whether the behavioral reactions differ by income and health status. We find women in East Germany are more affected than those in West Germany. In particular, unemployment rates of 60 to 62 year-old women increase more in East than in West Germany. East German women are less likely to be inactive. Furthermore, we find suggestive evidence for slightly higher employment effects for 60 and 61 year-old women with low income, poor health, and women without children.

The main heterogeneity of the reform effects results from the persistence of labor market statuses. Unemployed or inactive women remained in their respective status. For these women, the time between employment exit and retirement entry was simply extended, and the period of pension benefits receipt shortened. This is a large negative wealth shock for this group only partly compensated by lower deductions. Employed women were able to compensate this wealth shock by continuing to work and to increase their pension entitlements. 


\section{References}

Atalay, K. and Barrett, G. F. (2015). The impact of age pension eligibility age on retirement and program dependence: Evidence from an Australian experiment. Review of Economics and Statistics, 97(1):71-87.

Borghans, L., Gielen, A. C., and Luttmer, E. F. P. (2014). Social Support Substitution and the Earnings Rebound: Evidence from a Regression Discontinuity in Disability Insurance Reform. American Economic Journal: Economic Policy, 6(4):34-70.

Börsch-Supan, A. and Wilke, C. B. (2004). The German public pension system: how it was, how it will be. Nber discussion paper, National Bureau of Economic Research.

Coe, N. B. and Haverstick, K. (2010). Measuring the spillover to disability insurance due to the rise in the full retirement age. Boston College Center for Retirement Research Working Paper, (2010-21).

Cribb, J., Emmerson, C., and Tetlow, G. (2014). Labour supply effects of increasing the female state pension age in the UK from age 60 to 62. IFS Working Papers.

Deutsche Rentenversicherung (2015). Rentenversicherung in Zeitreihen 2015. DRVSchriften 22.

Duggan, M., Singleton, P., and Song, J. (2007). Aching to retire? the rise in the full retirement age and its impact on the social security disability rolls. Journal of Public Economics, 91(7):1327-1350.

Engels, B., Geyer, J., and Haan, P. (2016). Pension incentives and early retirement. DIW Discussion Paper 1617.

Fachinger, U. and Himmelreicher, R. K. (2006). Die Bedeutung des Scientific Use Files Vollendete Versichertenleben 2004 (SUFVVL2004) aus der Perspektive der Ökonomik. Deutsche Rentenversicherung, 9-10:562-582.

Giesecke, M. N. and Kind, M. (2013). Bridge unemployment in Germany: Response in labour supply to an increased early retirement age. Ruhr Economic Paper, (410).

Grogger, J. and Wunsch, C. (2012). Unemployment insurance and departures from employment: Evidence from a German reform.

Hanel, B. and Riphahn, R. T. (2012). The timing of retirement - New evidence from Swiss female workers. Labour Economics, 19(5):718-728.

Himmelreicher, R. K. and Stegmann, M. (2008). New Possibilities for Socio-Economic Research through Longitudinal Data from the Research Data Centre of the German Federal Pension Insurance (FDZ-RV). Schmollers Jahrbuch, 128(4):647-660.

Inderbitzin, L., Staubli, S., and Zweimüller, J. (2016). Extended unemployment benefits and early retirement: Program complementarity and program substitution. American Economic Journal: Economic Policy, 8(1):253-288.

Karlström, A., Palme, M., and Svensson, I. (2008). The employment effect of stricter rules for eligibility for DI: Evidence from a natural experiment in Sweden. Journal of Public Economics, 92(10-11):2071-2082. 
Lalive, R. and Staubli, S. (2014). How does raising women's full retirement age affect labor supply, income and mortality? Evidence from Switzerland.

Lee, D. S. and Lemieux, G. F. (2010). Regression discontinuity designs in economics. Journal of Economic Literature, American Economic Association, 48(2):281-355.

Li, X. and Maestas, N. (2008). Does the rise in the full retirement age encourage disability benefits applications? evidence from the health and retirement study. Evidence from the Health and Retirement Study (September 1, 2008). Michigan Retirement Research Center Research Paper, (2008-198).

Manoli, D. S. and Weber, A. (2016). The effects of the early retirement age on retirement decisions. NBER Working Paper w22561.

Mastrobuoni, G. (2009). Labor supply effects of the recent social security benefit cuts: Empirical estimates using cohort discontinuities. Journal of Public Economics, 93(11):12241233 .

OECD (2006). Live Longer, Work Longer. Ageing and Employment Policies. OECD Publishing.

OECD (2011). Pensions at a Glance 2011. OECD Pensions at a Glance. OECD Publishing.

OECD (2015). Pensions at a Glance 2015: OECD and G20 indicators. OECD Pensions at a Glance. OECD Publishing.

Oguzoglu, U., Polidano, C., and Vu, H. (2016). Impacts from delaying access to retirement benefits on welfare receipt and expenditure: Evidence from a natural experiment. IZA Discussion Paper 10014.

Seibold, A. (2016). Statutory ages and retirement: Evidence from Germany. Working paper, London School of Economics.

Staubli, S. (2011). The impact of stricter criteria for disability insurance on labor force participation. Journal of Public Economics, 95(9-10):1223-1235.

Staubli, S. and Zweimüller, J. (2013). Does raising the early retirement age increase employment of older workers? Journal of Public Economics, 108:17-32. 


\section{A. Pension types}

Table 4: Pathways to pensions

\begin{tabular}{|c|c|c|c|c|}
\hline Pension type & $\begin{array}{l}\text { Early } \\
\text { (ERA) }\end{array}$ & $\begin{array}{l}\text { Normal } \\
\text { (NRA) }\end{array}$ & $\begin{array}{l}\text { Contribution } \\
\text { Period }\end{array}$ & Notes \\
\hline Regular & - & $65 \Rightarrow 67$ & 5 & $\begin{array}{l}\text { Retirement age has } \\
\text { been increased to } \\
67 \text { since 2012; fully } \\
\text { phased-in with cohort } \\
1964\end{array}$ \\
\hline Women & 60 & 65 & 15 (10 after age 40$)$ & $\begin{array}{l}\text { Abolished for cohorts } \\
\text { born after } 1951\end{array}$ \\
\hline Invalidity & $60 \Rightarrow 62$ & $63 \Rightarrow 65$ & 35 & $\begin{array}{l}\text { Starting with cohort } \\
1952 \text { ERA and NRA } \\
\text { increase by two years; } \\
\text { fully phased-in with co- } \\
\text { hort } 1964\end{array}$ \\
\hline \multirow[t]{2}{*}{ Long-term insured } & $63 \Rightarrow 65$ & $65 \Rightarrow 67$ & 35 & $\begin{array}{l}\text { ERA increases to } 65 \text {, } \\
\text { NRA increases to } 67 \text {; } \\
\text { fully phased-in with co- } \\
\text { hort } 1964\end{array}$ \\
\hline & - & $63 \Rightarrow 65$ & 45 & $\begin{array}{l}\text { Special scheme for peo- } \\
\text { ple with particularly } \\
\text { long insurance records }\end{array}$ \\
\hline $\begin{array}{l}\text { Unemployed/old-age } \\
\text { part-time }\end{array}$ & 63 & 65 & 15 (8 in last 10 years) & $\begin{array}{l}\text { Abolished for cohorts } \\
\text { born after } 1951\end{array}$ \\
\hline Disability pension & no threshold & $63 \Rightarrow 65$ & 5 (3 in last 5 years $)$ & $\begin{array}{l}\text { Maximum deductions } \\
\text { amount to } 10.8 \% \text {; } \\
\text { since } 2012 \text { the NRA } \\
\text { increases to } 65 ; \text { fully } \\
\text { phased in with cohort } \\
1964\end{array}$ \\
\hline
\end{tabular}

Notes: The ERA denotes the age at which the pension type becomes available if eligibility criteria are fulfilled. Early retirement is associated with deductions of $0.3 \%$ per month before the NRA. The NRA denotes the age at which a full pension, i.e. without deductions becomes available. 


\section{B. Results for 58 and 59 year old women}

Table 5: Linear regression results, age 58-59

\begin{tabular}{lcccc}
\hline & Employment & Unemployment & Disability pension & Inactivity \\
\hline$D_{i}$ & 0.015 & 0.004 & -0.000 & -0.017 \\
Month of birth & $(0.0259)$ & $(0.0099)$ & $(0.0185)$ & $(0.0169)$ \\
& 0.000 & -0.000 & -0.002 & 0.000 \\
$D_{i} \times$ Month of birth & $(0.0030)$ & $(0.0011)$ & $(0.0017)$ & $(0.0020)$ \\
& 0.000 & -0.002 & 0.003 & 0.001 \\
Children & $(0.0041)$ & $(0.0016)$ & $(0.0024)$ & $(0.0024)$ \\
& 0.006 & $-0.017^{*}$ & -0.008 & -0.007 \\
West & $(0.0131)$ & $(0.0100)$ & $(0.0162)$ & $(0.0137)$ \\
& 0.022 & $-0.078^{* * *}$ & $0.019^{*}$ & $0.026^{* *}$ \\
Constant & $(0.0174)$ & $(0.0086)$ & $(0.0101)$ & $(0.0121)$ \\
& $0.579^{* * *}$ & $0.272^{* * *}$ & $0.085^{* * *}$ & $0.126^{* * *}$ \\
\hline N & $(0.0345)$ & $(0.0165)$ & $(0.0282)$ & $(0.0264)$ \\
$R^{2}$ & 3,771 & 3,771 & 3,771 & 3,771 \\
Pre-treatment mean & 0.033 & 0.053 & 0.004 & 0.006 \\
\hline
\end{tabular}

Notes: Robust standard errors in parentheses. Significance levels: *** $\mathrm{p}<0.01, * * \mathrm{p}<0.05, * \mathrm{p}<0.1$. All linear regressions include calendar month fixed effects, income group dummies, and linear trends in the running variable on both sides of the policy cutoff. Standard errors are clustered by month of birth.

Source: VSKT 2014, own calculations 
Figure 13: Local linear regression plots, age 58-59

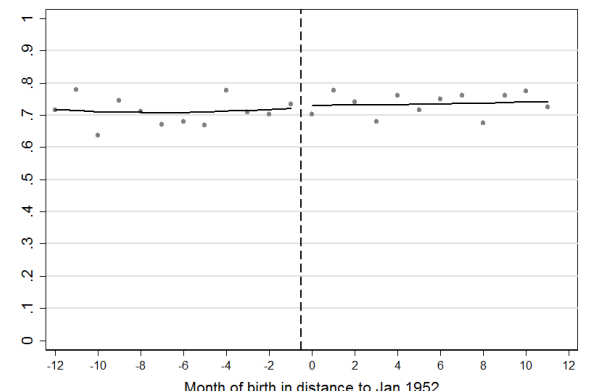

(a) Employment

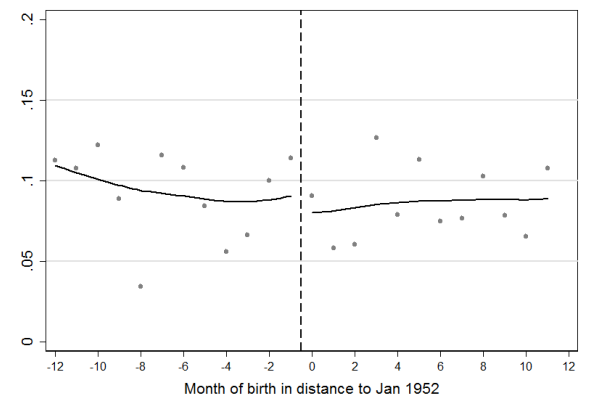

(c) Disability pension

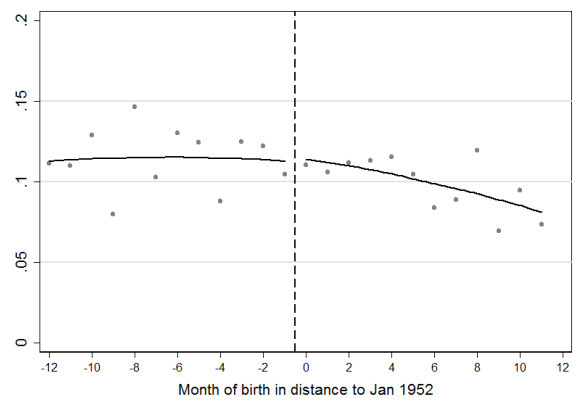

(b) Unemployment

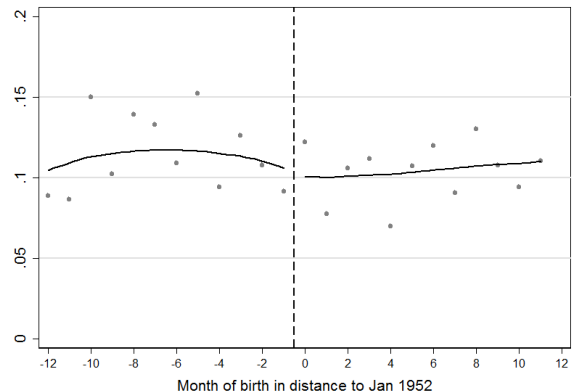

(d) Inactivity

Notes: Scatter plots display mean outcome values using monthly bins. Local linear regression plots are based on triangular kernel functions with a bandwidth of 12 months.

Source: VSKT 2014, own calculations

Table 6: Subgroup analysis - linear regression results, age 58-59

\begin{tabular}{lccccc}
\hline & Employment & Unemployment & Disability pension & Inactivity & $\mathrm{N}$ \\
\hline Baseline & 0.015 & 0.004 & -0.000 & -0.017 & 3771 \\
West Germany & $(0.0259)$ & $(0.0099)$ & $(0.0185)$ & $(0.0169)$ & \\
& -0.007 & 0.001 & 0.018 & -0.013 & 2727 \\
East Germany & $(0.0383)$ & $(0.0134)$ & $(0.0222)$ & $(0.0195)$ & \\
& 0.065 & 0.021 & -0.044 & -0.035 & 1044 \\
Low income & $(0.0570)$ & $(0.0280)$ & $(0.0357)$ & $(0.0290)$ & \\
& 0.059 & -0.048 & -0.010 & -0.012 & 1046 \\
Poor health & $(0.0460)$ & $(0.0332)$ & $(0.0382)$ & $(0.0282)$ & \\
& 0.017 & 0.009 & 0.010 & -0.012 & 988 \\
Children & $(0.0597)$ & $(0.0408)$ & $(0.0630)$ & $(0.0300)$ & \\
& 0.023 & 0.007 & 0.013 & $-0.034^{*}$ & 3198 \\
No children & $(0.0255)$ & $(0.0122)$ & $(0.0204)$ & $(0.0198)$ & \\
& -0.007 & -0.019 & -0.084 & $0.064^{*}$ & 573 \\
& $(0.0486)$ & $(0.0226)$ & $(0.0507)$ & $(0.0318)$ & \\
\hline
\end{tabular}

Notes: Robust standard errors in parentheses. Significance levels: *** $\mathrm{p}<0.01, * * \mathrm{p}<0.05, * \mathrm{p}<0.1$. All linear regressions include calendar month fixed effects, income group dummies, and linear trends in the running variable (month of birth) on both sides of the policy cutoff. Standard errors are clustered by month of birth.

Source: VSKT 2014, own calculations 


\section{Robustness and validity of the empirical strategy}

We identified several potential threats to our identification strategy. These are discontinuities in covariates, and the turn of the year effect, and bias due to sample selection. While Section 5 describes our empirical strategy, we address all possible identification threats in greater detail in this section, and check whether our results are robust to several alternative specifications of the empirical model.

\section{C.1. Discontinuities in covariates}

A main concern for every analysis based on cohort discontinuities is that something other than the policy change of interest is affecting the relevant cohorts. This may lead to discontinuities in covariates that may in turn affect the outcome variables of interest. One way to account for this concern is to check for discontinuities in covariates that should not be affected by the reform. The analysis of outcomes for 58 and 59 year-old women can be interpreted as a test for covariate-discontinuities. However, although these age groups are not directly affected by the reform, they may have adapted their employment behavior in anticipation of the ERA increase. Consequently, it is difficult to find covariates that are truly unaffected by the reform. We compare several time-invariant covariates as average and sum of pension points, health status, number of children, and contribution period by month of birth and do not find any discontinuities between cohorts. We find that women who are born after the policy cutoff are significantly less likely to be eligible for the pension for long-term insured individuals, however, this may be due to the fact that the 1951 cohort is older at the point of data collection and therefore more likely to have accumulated the required 35 years of pension contribution years.

Table 7: Test for discontinuities in covariates

\begin{tabular}{lcc|ccc|c}
\hline Variable & \multicolumn{2}{c}{ Linear RDD } & \multicolumn{2}{c}{ Quadratic RDD } & Sample mean \\
\hline Average pension points (month) & -0.000 & $(0.000)$ & 0.001 & $(0.002)$ & 0.064 \\
Sum of pension points & -0.444 & $(0.714)$ & 0.009 & $(0.787)$ & 31.66 \\
Poor health status & 0.015 & $(0.026)$ & 0.004 & $(0.032)$ & 0.262 \\
Has at least one child & 0.000 & $(0.032)$ & 0.082 & $(0.065)$ & 0.848 \\
Contribution period & 0.296 & $(0.353)$ & 0.082 & $(0.445)$ & 37.19 \\
Sum contribution months after 40 & -0.820 & $(2.204)$ & -1.724 & $(2.837)$ & 213.2 \\
\hline
\end{tabular}

Notes: All regressions include calendar month fixed effects, income group dummies, and linear or quadratic trends in the running variable (month of birth) on both sides of the policy cutoff. Standard errors (in parentheses) are clustered by month of birth.

Source: VSKT2014, own calculations

\section{C.2. Difference-in-discontinuities approach}

We refer to differences between women born at the end of a year in comparison to women who were born at the beginning of a year as turn of the year effect. In particular, there may be discontinuities in labor market outcomes for women born between December and January that are unrelated to the ERA increase reform. In order to address this concern, we performed a difference-in-discontinuities analysis using the discontinuity between cohorts born in 1950 and 1951 as counterfactual with a hypothetical policy-cutoff in the running variable at the turn of the year. The difference-in-discontinuities estimation is implemented by interacting the regression equation with an indicator function $T_{i}$, equal to one for the real sample around the actual reform cutoff-date, and zero otherwise. The results for 60-61 
and 58-59 year-old women are displayed in Table 8 and Table 9). Reassuringly, the results are similar to those of the baseline specification presented in Section 6.1. The coefficients of the interaction term $T_{i} * D_{i}$ fo not differ significantly from the corresponding coefficients in Tables 1 and 5 . We conclude that discontinuities between cohorts can be attributed to the ERA increase and therefore select a standard RD framework as our baseline specification.

Table 8: Difference-in-discontinuities results, age 60-61

\begin{tabular}{lcccc}
\hline & Employment & Unemployment & Disability pension & Inactivity \\
\hline$T_{i} \times D_{i}$ & $0.172^{* * *}$ & $0.031^{* *}$ & -0.017 & $0.062^{* * *}$ \\
$T_{i} \times$ Month of birth & $(0.0241)$ & $(0.0145)$ & $(0.0212)$ & $(0.0161)$ \\
& -0.002 & 0.001 & $-0.004^{* * *}$ & 0.001 \\
$T_{i} \times D_{i} \times$ Month of birth & $(0.0021)$ & $(0.0012)$ & $(0.0014)$ & $(0.0011)$ \\
& -0.001 & -0.001 & $0.007^{* *}$ & -0.001 \\
$D_{i}$ & $(0.0051)$ & $(0.0022)$ & $(0.0032)$ & $(0.0023)$ \\
\multirow{4}{*}{ Month of birth } & -0.022 & 0.009 & 0.021 & -0.011 \\
& $(0.0248)$ & $(0.0097)$ & $(0.0148)$ & $(0.0101)$ \\
$D_{i} \times$ Month of birth & $0.003^{*}$ & -0.001 & $0.002^{*}$ & -0.000 \\
Constant & $(0.0020)$ & $(0.0014)$ & $(0.0013)$ & $(0.0011)$ \\
& -0.002 & -0.000 & -0.004 & 0.001 \\
& $(0.0036)$ & $(0.0017)$ & $(0.0025)$ & $(0.0014)$ \\
$\mathrm{N}$ & $0.536^{* * *}$ & $0.075^{* * *}$ & $0.102^{* * *}$ & $0.061^{* * *}$ \\
$R^{2}$ & $(0.0118)$ & $(0.0056)$ & $(0.0085)$ & $(0.0072)$ \\
\hline
\end{tabular}

Notes: Robust standard errors in parentheses. Significance levels: *** $\mathrm{p}<0.01, * * \mathrm{p}<0.05, * \mathrm{p}<0.1$. All linear regressions include calendar month fixed effects, income group dummies, and linear trends in the running variable (month of birth) on both sides of the policy cutoff. Standard errors are clustered by month of birth.

Source: VSKT2014, own calculations

Table 9: Differences-in-discontinuities results, age 58-59

\begin{tabular}{lcccc}
\hline & Employment & Unemployment & Disability pension & Inactivity \\
\hline$T_{i} \times D_{i}$ & 0.020 & 0.002 & -0.021 & -0.015 \\
$T_{i} \times$ Month of birth & $(0.0277)$ & $(0.0083)$ & $(0.0186)$ & $(0.0195)$ \\
\multirow{2}{*}{$T_{i} \times D_{i} \times$ Month of birth } & -0.001 & $0.002^{* *}$ & $-0.003^{* *}$ & $0.002^{*}$ \\
& $(0.0020)$ & $(0.0009)$ & $(0.0013)$ & $(0.0012)$ \\
$D_{i}$ & 0.002 & $-0.005^{* *}$ & $0.006^{* *}$ & -0.001 \\
& $(0.0048)$ & $(0.0018)$ & $(0.0028)$ & $(0.0030)$ \\
Month of birth & -0.011 & -0.005 & $0.025^{*}$ & 0.001 \\
& $(0.0274)$ & $(0.0098)$ & $(0.0129)$ & $(0.0171)$ \\
$D_{i} \times$ Month of birth & $0.003^{*}$ & $-0.001^{*}$ & 0.001 & $-0.002^{* *}$ \\
Constant & $(0.0013)$ & $(0.0007)$ & $(0.0010)$ & $(0.0009)$ \\
& -0.002 & 0.001 & -0.003 & 0.003 \\
$\mathrm{~N}$ & $(0.0034)$ & $(0.0012)$ & $(0.0021)$ & $(0.0022)$ \\
$R^{2}$ & $0.717^{* * *}$ & $0.119^{* * *}$ & $0.079^{* * *}$ & $0.113^{* * *}$ \\
\hline
\end{tabular}

Notes: Robust standard errors in parentheses. Significance levels: *** $\mathrm{p}<0.01, * * \mathrm{p}<0.05, * \mathrm{p}<0.1$. All linear regressions include calendar month fixed effects, income group dummies, and linear trends in the running variable (month of birth) on both sides of the policy cutoff. Standard errors are clustered by month of birth.

Source: VSKT2014, own calculations 


\section{C.3. Sample selection}

A major concern arises due to the selection of the sample by the eligibility criteria of the pension for women. Specifically, women born in 1951 may select into the sample by prolonging their pension contribution period in order to be eligible for early retirement. In contrast, women born in 1952 do not have the same incentives to fulfill the eligibility criteria. The eligibility criteria for claiming a pension for women are: (i) at least 15 years of pension insurance contributions; and (ii) at least 10 years of pension insurance contributions after the age of 40 .

Consequently, we expect bunching in the density distribution after 15 contribution years for the 1951 cohort, but not for the 1952 cohort. However, when the reform was introduced in 1999, women born in 1951 and 1952 were already 47-48 years old. At that age, most women have already collected at least 5 contribution years. Therefore, cohorts have different incentives primarily with respect to the second eligibility criterion of a contribution period of at least 10 years after age 40. We show in Figure 15 and Figure 17 that there is no bunching: neither after 15 years, nor after 121 contribution months for the 1951 cohort, when compared to the 1952 cohort. Seibold (2016) also looks at bunching in pension contribution years and finds only little bunching at the relevant cutoffs for women. Furthermore, we test for a discontinuity (1) in the fraction of women fulfilling the eligibility criteria for early retirement, (2) the number of contribution years, (3) the number of contribution months after age 40, (4) eligibility for the old-age pension for the long term insured, and (5) the sum of years worked up to age 60 . We find that there is no significant discontinuity at the cohort-cutoff. The corresponding local linear and local polynomial regression plots for the fraction of women fulfilling the eligibility criteria are displayed in Figure 19. We conclude that bias due to sample selection is negligible.

Figure 15: Distribution of contribution years by cohort

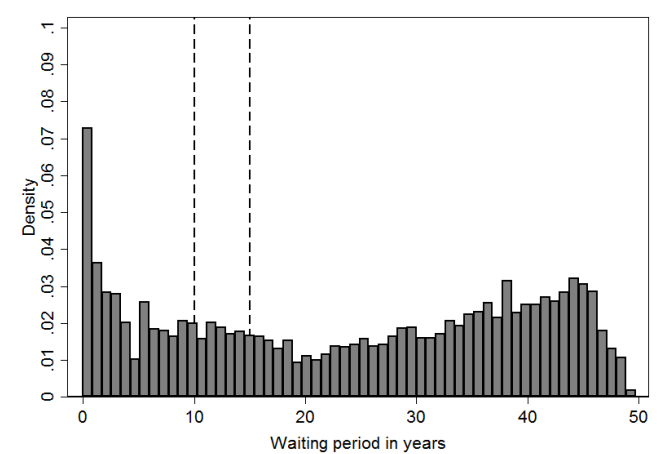

(a) 1951 Cohort

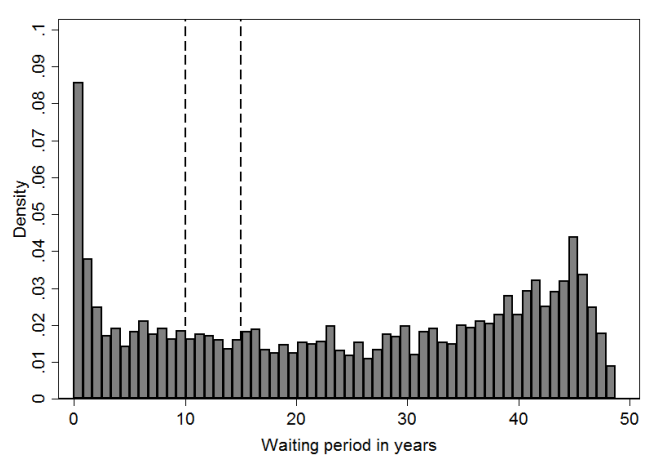

(b) 1952 Cohort

Notes: Eligibility requires 15 years of contributions. Source: VSKT2014, own calculations 
Figure 17: Distribution of contribution months after age 40 by cohort

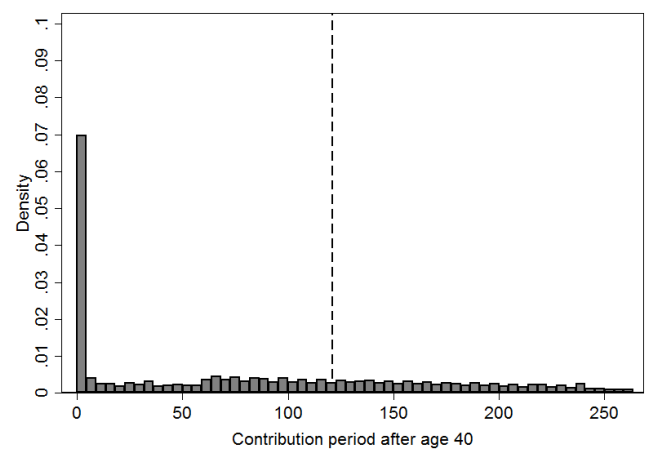

(a) 1951 Cohort

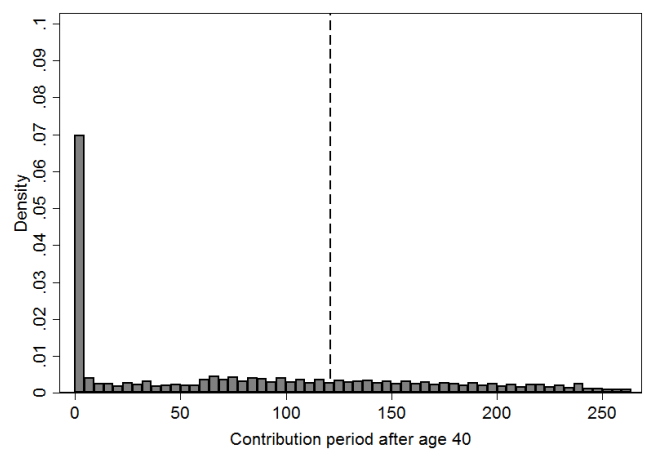

(b) 1952 Cohort

Notes: Eligibility requires 121 contribution months after age 40. Source: VSKT2014, own calculations

Figure 19: Testing for discontinuity in fulfillment of eligibility criteria

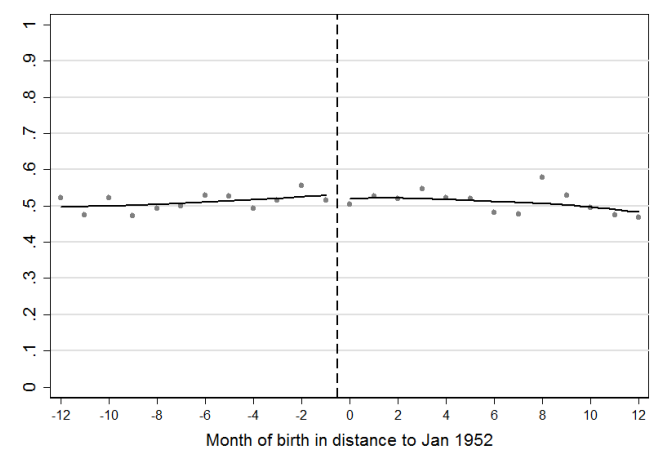

(a) Local linear regression

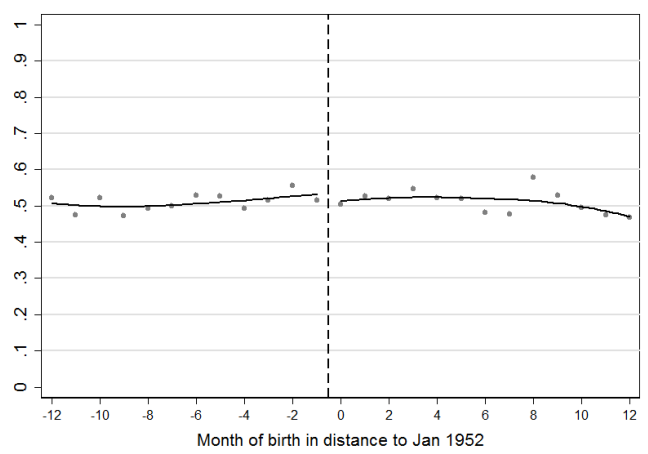

(b) Local quadratic regression

Notes: Scatter plots display mean outcome values using monthly bins. Local linear regression plots are based on triangular kernel functions with a bandwidth of 12 months.

Source: VSKT2014, own calculations 


\section{C.4. RDD results for all women}

Table 10: Linear regression for all women, age 60-61

\begin{tabular}{lcccc}
\hline & Employment & Unemployment & Disability pension & Inactivity \\
\hline$D_{i}$ & $0.076^{* * *}$ & $0.035^{* * *}$ & 0.019 & 0.012 \\
\multirow{3}{*}{ Month of birth } & $(0.0191)$ & $(0.0067)$ & $(0.0175)$ & $(0.0202)$ \\
& 0.002 & -0.001 & -0.000 & -0.001 \\
$D_{i} \times$ Month of birth & $(0.0021)$ & $(0.0009)$ & $(0.0013)$ & $(0.0021)$ \\
& -0.003 & -0.000 & -0.000 & 0.004 \\
Children & $(0.0031)$ & $(0.0011)$ & $(0.0023)$ & $(0.0029)$ \\
& $0.174^{* * *}$ & $0.030^{* * *}$ & $0.036^{* * *}$ & $-0.277^{* * *}$ \\
West & $(0.0105)$ & $(0.0059)$ & $(0.0085)$ & $(0.0144)$ \\
& $-0.073^{* * *}$ & $-0.057^{* * *}$ & $-0.031^{* * *}$ & $0.212^{* * *}$ \\
Constant & $(0.0199)$ & $(0.0105)$ & $(0.0106)$ & $(0.0137)$ \\
& $0.230^{* * *}$ & $0.154^{* * *}$ & $0.101^{* * *}$ & $0.367^{* * *}$ \\
\hline N & $(0.0219)$ & $(0.0112)$ & $(0.0196)$ & $(0.0249)$ \\
$R^{2}$ & 7289 & 7289 & 7289 & 7289 \\
\hline Pre-treatment mean & 0.055 & 0.042 & 0.007 & 0.109 \\
\hline
\end{tabular}

Notes: Robust standard errors in parentheses. Significance levels: *** $\mathrm{p}<0.01, * * \mathrm{p}<0.05, * \mathrm{p}<0.1$. All linear regressions include calendar month fixed effects, income group dummies, and linear trends in the running variable (month of birth) on both sides of the policy cutoff. Standard errors are clustered by month of birth.

Source: VSKT2014, own calculations

Table 11: Linear regression results for all women, age 58-59

\begin{tabular}{lcccc}
\hline & Employment & Unemployment & Disability pension & Inactivity \\
\hline$D_{i}$ & 0.006 & 0.015 & 0.021 & $-0.044^{* *}$ \\
\multirow{3}{*}{ Month of birth } & $(0.0157)$ & $(0.0103)$ & $(0.0141)$ & $(0.0205)$ \\
& 0.002 & -0.001 & -0.001 & -0.001 \\
$D_{i} \times$ Month of birth & $(0.0019)$ & $(0.0012)$ & $(0.0010)$ & $(0.0022)$ \\
& -0.003 & -0.002 & -0.001 & $0.005^{*}$ \\
Children & $(0.0024)$ & $(0.0013)$ & $(0.0019)$ & $(0.0026)$ \\
& $0.210^{* * *}$ & $0.035^{* * *}$ & $0.024^{* *}$ & $-0.265^{* * *}$ \\
West & $(0.0115)$ & $(0.0059)$ & $(0.0090)$ & $(0.0113)$ \\
& $-0.120^{* * *}$ & $-0.073^{* * *}$ & $-0.028^{* *}$ & $0.207^{* * *}$ \\
Constant & $(0.0170)$ & $(0.0077)$ & $(0.0104)$ & $(0.0133)$ \\
& $0.340^{* * *}$ & $0.204^{* * *}$ & $0.081^{* * *}$ & $0.410^{* * *}$ \\
\hline N & $(0.0215)$ & $(0.0129)$ & $(0.0190)$ & $(0.0240)$ \\
$R^{2}$ & 7289 & 7289 & 7289 & 7289 \\
Pre-treatment mean & 0.066 & 0.058 & 0.005 & 0.099 \\
\hline
\end{tabular}

Notes: Robust standard errors in parentheses. Significance levels: *** $\mathrm{p}<0.01, * * \mathrm{p}<0.05, * \mathrm{p}<0.1$. All linear regressions include calendar month fixed effects, income group dummies, and linear trends in the running variable (month of birth) on both sides of the policy cutoff. Standard errors are clustered by month of birth.

Source: VSKT2014, own calculations 


\section{C.5. RDD results without covariates}

Table 12: Regression without covariates, age 60-61

\begin{tabular}{lcccc}
\hline & Employment & Unemployment & Disability pension & Inactivity \\
\hline$D_{i}$ & $0.145^{* * *}$ & $0.050^{* * *}$ & -0.003 & $0.053^{* * *}$ \\
\multirow{4}{*}{ Month of birth } & $(0.0287)$ & $(0.0121)$ & $(0.0239)$ & $(0.0119)$ \\
& 0.002 & -0.002 & -0.001 & 0.000 \\
$D_{i} \times$ Month of birth & $(0.0030)$ & $(0.0010)$ & $(0.0021)$ & $(0.0009)$ \\
& -0.002 & -0.000 & 0.003 & 0.001 \\
Constant & $(0.0043)$ & $(0.0016)$ & $(0.0030)$ & $(0.0018)$ \\
& $0.543^{* * *}$ & $0.065^{* * *}$ & $0.108^{* * *}$ & $0.058^{* * *}$ \\
$\mathrm{~N}$ & $(0.0214)$ & $(0.0059)$ & $(0.0180)$ & $(0.0064)$ \\
$R^{2}$ & 3771 & 3771 & 3771 & 3771 \\
& 0.025 & 0.003 & 0.000 & 0.012 \\
\hline
\end{tabular}

Notes: Robust standard errors in parentheses. Significance levels: *** $\mathrm{p}<0.01, * * \mathrm{p}<0.05, * \mathrm{p}<0.1$. All regressions include linear trends in the running variable (month of birth) on both sides of the policy cutoff. Standard errors are clustered by month of birth.

Source: VSKT2014, own calculations

Table 13: Regression without covariates, age 58-59

\begin{tabular}{|c|c|c|c|c|}
\hline & Employment & Unemployment & Disability pension & Inactivity \\
\hline \multirow[t]{2}{*}{$D_{i}$} & 0.015 & 0.002 & 0.001 & -0.016 \\
\hline & $(0.0275)$ & $(0.0087)$ & $(0.0192)$ & $(0.0168)$ \\
\hline \multirow[t]{2}{*}{ Month of birth } & 0.000 & -0.000 & -0.002 & 0.000 \\
\hline & $(0.0032)$ & $(0.0010)$ & $(0.0018)$ & $(0.0020)$ \\
\hline \multirow{2}{*}{$D_{i} \times$ Month of birth } & 0.001 & $-0.003^{*}$ & 0.003 & 0.001 \\
\hline & $(0.0043)$ & $(0.0014)$ & $(0.0025)$ & $(0.0025)$ \\
\hline \multirow[t]{2}{*}{ Constant } & $0.712^{* * *}$ & $0.114^{* * *}$ & $0.081^{* * *}$ & $0.116^{* * *}$ \\
\hline & $(0.0198)$ & $(0.0078)$ & $(0.0144)$ & $(0.0131)$ \\
\hline $\mathrm{N}$ & 3771 & 3771 & 3771 & 3771 \\
\hline$R^{2}$ & 0.001 & 0.001 & 0.000 & 0.000 \\
\hline
\end{tabular}

Notes: Robust standard errors in parentheses. Significance levels: $* * * \mathrm{p}<0.01, * * \mathrm{p}<0.05, * \mathrm{p}<0.1$. All regressions include linear trends in the running variable (month of birth) on both sides of the policy cutoff. Standard errors are clustered by month of birth.

Source: VSKT2014, own calculations 


\section{C.6. RDD results with quadratic trends}

Table 14: Regression with quadratic trends, age 60-61

\begin{tabular}{lcccc}
\hline & Employment & Unemployment & Disability pension & Inactivity \\
\hline$D_{i}$ & $0.125^{* * *}$ & $0.032^{* *}$ & -0.045 & $0.071^{* * *}$ \\
& $(0.0318)$ & $(0.0156)$ & $(0.0301)$ & $(0.0152)$ \\
Month of birth & 0.010 & 0.006 & 0.013 & -0.003 \\
Month of birth ${ }^{2}$ & $(0.0101)$ & $(0.0044)$ & $(0.0098)$ & $(0.0049)$ \\
& 0.001 & $0.001^{*}$ & 0.001 & -0.000 \\
$D_{i} \times$ Month of birth & $(0.0008)$ & $(0.0003)$ & $(0.0007)$ & $(0.0004)$ \\
& -0.012 & -0.008 & -0.007 & -0.002 \\
$D_{i} \times$ Month of birth & \\
& $(0.0127)$ & $(0.0070)$ & $(0.0122)$ & $(0.0073)$ \\
Children & -0.001 & -0.001 & -0.002 & 0.001 \\
& $(0.0011)$ & $(0.0006)$ & $(0.0010)$ & $(0.0006)$ \\
West & 0.011 & -0.012 & -0.005 & -0.017 \\
& $(0.0164)$ & $(0.0119)$ & $(0.0130)$ & $(0.0127)$ \\
Constant & $0.051^{* *}$ & $-0.067^{* * *}$ & $0.021^{*}$ & $0.030^{* *}$ \\
& $(0.0207)$ & $(0.0124)$ & $(0.0111)$ & $(0.0114)$ \\
\hline $\mathrm{N}$ & $0.400^{* * *}$ & $0.201^{* * *}$ & $0.151^{* * *}$ & $0.066^{* * *}$ \\
$R^{2}$ & $(0.0366)$ & $(0.0203)$ & $(0.0339)$ & $(0.0221)$ \\
\hline
\end{tabular}

Notes: Robust standard errors in parentheses. Significance levels: ${ }^{* * *} \mathrm{p}<0.01,{ }^{* *} \mathrm{p}<0.05,{ }^{*} \mathrm{p}<0.1$. All regressions include calendar month fixed effects, income group dummies, and quadratic trends in the running variable (month of birth) on both sides of the policy cutoff. Standard errors are clustered by month of birth.

Source: VSKT2014, own calculations 
Figure 21: Local polynomial regression plots, age 60-61

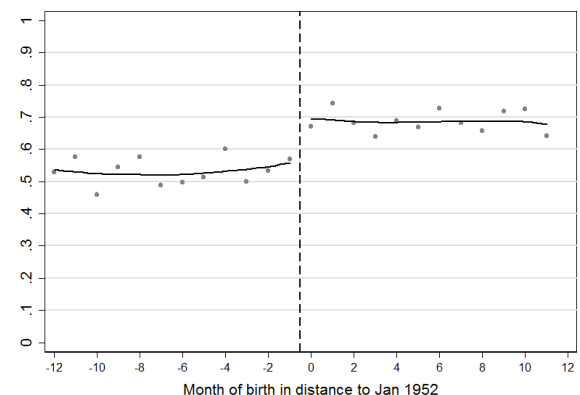

(a) Employment

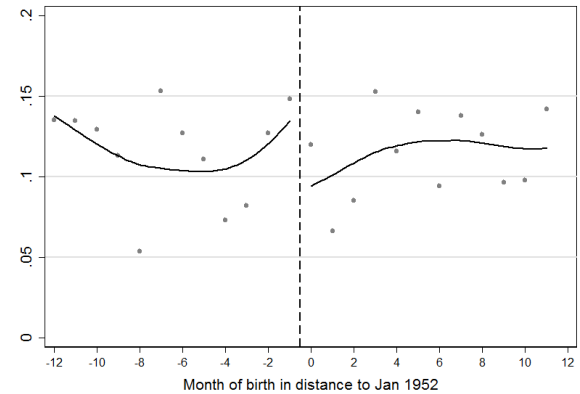

(c) Disability pension

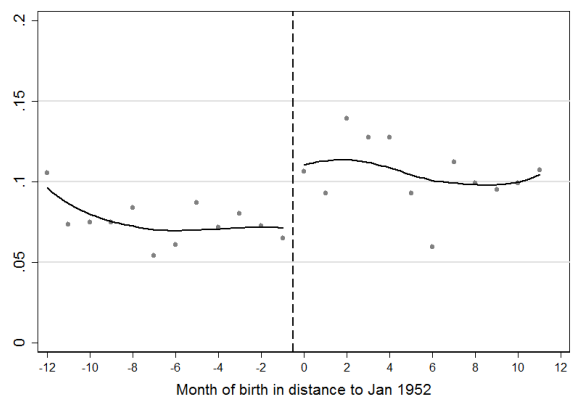

(b) Unemployment

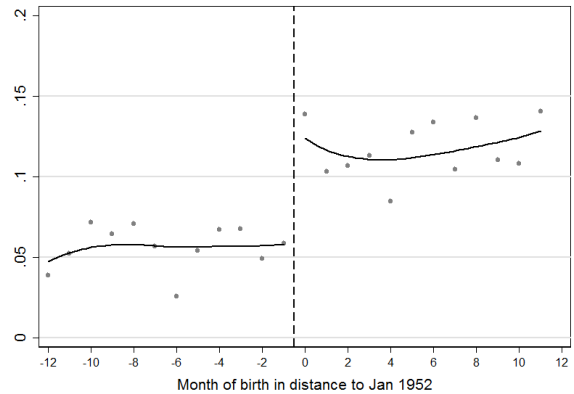

(d) Inactivity

Notes: Scatter plots display mean outcome values using monthly bins. Local linear regression plots are based on triangular kernel functions with a bandwidth of 12 months.

Source: VSKT2014, own calculations 
Table 15: Regression with quadratic trends, age 58-59

\begin{tabular}{lcccc}
\hline & Employment & Unemployment & Disability pension & Inactivity \\
\hline$D_{i}$ & -0.015 & -0.003 & -0.034 & $0.028^{*}$ \\
& $(0.0286)$ & $(0.0148)$ & $(0.0225)$ & $(0.0160)$ \\
Month of birth & 0.014 & -0.000 & 0.011 & $-0.017^{* * *}$ \\
& $(0.0081)$ & $(0.0053)$ & $(0.0083)$ & $(0.0042)$ \\
Month of birth ${ }^{2}$ & 0.001 & 0.000 & 0.001 & $-0.001^{* * *}$ \\
& $(0.0007)$ & $(0.0004)$ & $(0.0006)$ & $(0.0003)$ \\
$D_{i} \times$ Month of birth & -0.014 & 0.002 & -0.007 & $0.016^{* *}$ \\
& $(0.0117)$ & $(0.0059)$ & $(0.0099)$ & $(0.0071)$ \\
$D_{i} \times$ Month of birth ${ }^{2}$ & -0.001 & -0.000 & -0.001 & $0.002^{* *}$ \\
& $(0.0010)$ & $(0.0004)$ & $(0.0008)$ & $(0.0006)$ \\
Children & 0.007 & -0.017 & -0.007 & -0.008 \\
& $(0.0132)$ & $(0.0100)$ & $(0.0161)$ & $(0.0138)$ \\
West & 0.022 & $-0.078^{* * *}$ & $0.018^{*}$ & $0.027^{* *}$ \\
\multirow{2}{*}{ Constant } & $(0.0174)$ & $(0.0086)$ & $(0.0102)$ & $(0.0120)$ \\
& $0.610^{* * *}$ & $0.273^{* * *}$ & $0.115^{* * *}$ & $0.085^{* * *}$ \\
\hline $\mathrm{N}$ & $(0.0361)$ & $(0.0210)$ & $(0.0307)$ & $(0.0245)$ \\
$R^{2}$ & 3771 & 3771 & 3771 & 3771 \\
\hline
\end{tabular}

Notes: Robust standard errors in parentheses. Significance levels: $* * * \mathrm{p}<0.01, * * \mathrm{p}<0.05,{ }^{*} \mathrm{p}<0.1$. All regressions include calendar month fixed effects, income group dummies, and quadratic trends in the running variable on both sides of the policy cutoff. Standard errors are clustered by month of birth.

Source: VSKT2014, own calculations

Figure 23: Local polynomial regression plots, age 58-59

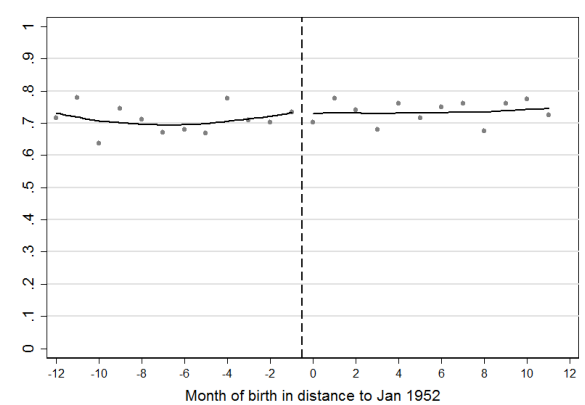

(a) Employment

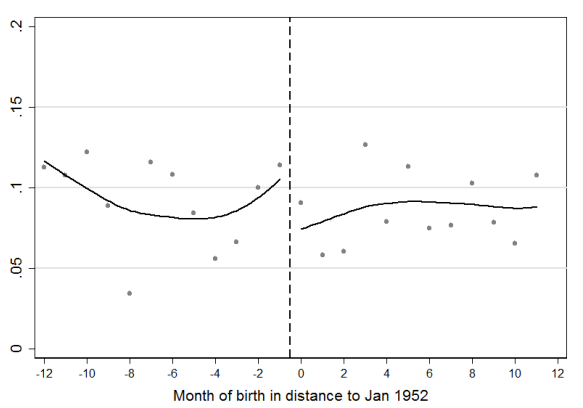

(c) Disability pension

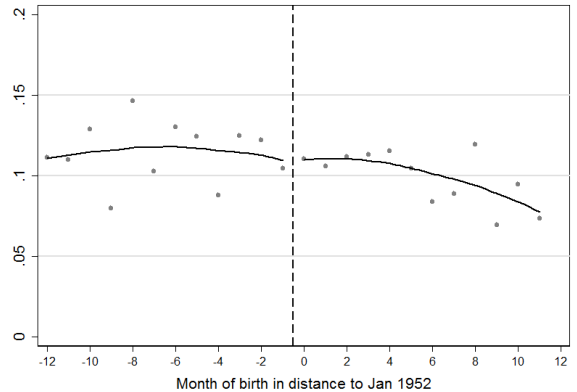

(b) Unemployment

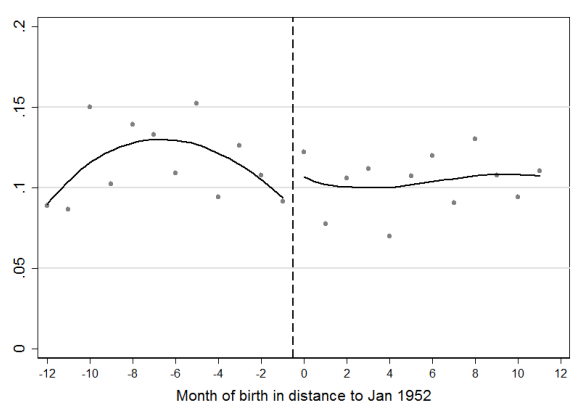

(d) Inactivity

Notes: Local polynomial regressions of 2nd degree, with triangular kernel and a bandwidth of 12 months. Source: VSKT2014, own calculations 


\section{Sample characteristics: early vs. late retirement}

Table 16: Comparison of women who retire early $(<62)$ and late $(\geq 62)$

\begin{tabular}{|c|c|c|c|c|c|c|}
\hline & \multicolumn{2}{|c|}{ Retire late $(\geq 62)$} & \multicolumn{2}{|c|}{ Retire early $(<62)$} & \multirow[b]{2}{*}{ Diff } & \multirow[b]{2}{*}{ t-value } \\
\hline & Mean & SD & Mean & SD & & \\
\hline Average monthly pension points & 0.068 & 0.025 & 0.064 & 0.023 & -0.004 & -3.15 \\
\hline Sum of pension points & 35.082 & 14.031 & 31.425 & 12.185 & -3.657 & -5.65 \\
\hline Poor health status & 0.220 & 0.414 & 0.282 & 0.450 & 0.062 & 2.78 \\
\hline Has at least one child & 0.863 & 0.344 & 0.858 & 0.350 & -0.005 & -0.28 \\
\hline Sum of children & 1.697 & 1.134 & 1.674 & 1.068 & -0.024 & -0.43 \\
\hline Sum contribution months after 40 & 215.118 & 36.650 & 211.511 & 35.752 & -3.608 & -1.97 \\
\hline Eligible for early retirement with 63 & 0.906 & 0.292 & 0.918 & 0.275 & 0.012 & 0.84 \\
\hline contribution period in years & 38.423 & 7.448 & 36.781 & 6.704 & -1.642 & -4.67 \\
\hline Employed at $60^{t h}$ birthday & 0.711 & 0.454 & 0.480 & 0.500 & -0.231 & -9.35 \\
\hline Unemployed at $60^{t h}$ birthday & 0.062 & 0.242 & 0.135 & 0.342 & 0.073 & 4.54 \\
\hline $\mathrm{N}$ & 1288 & & 557 & & 1845 & \\
\hline
\end{tabular}

Notes: Including all women born in 1951 who fulfill the eligibility criteria for the early pension for women. Source: VSKT2014, own calculations 